\title{
带准备时间的柔性流水车间多序列有限 缓冲区排产优化问题
}

\author{
韩忠华 1,2,3,4 张 权 ${ }^{2}$ 史海波 ${ }^{1,3,4}$ 张竞元 $^{2}$ \\ (1. 中国科学院沈阳自动化研究所 沈阳 110016; \\ 2. 沈阳建筑大学信息与控制工程学院 沈阳 110168 ; \\ 3. 中国科学院网络化控制系统重点实验室 沈阳 110016; \\ 4. 中国科学院机器人与智能制造创新研究院 沈阳 110016)
}

\begin{abstract}
摘要: 针对带准备时间的柔性流水车间多序列有限缓冲区排产优化问题, 提出一种改进的紧致遗传算法(Improved compact genetic algorithm, ICGA)与局部指派规则结合的方法来解决该问题。全局优化过程采用改进的紧致遗传算法, 为了克服紧致遗 传算法(Compact genetic algorithm, CGA)易早熟收玫的问题, 提出一种基于高斯映射的概率模型更新方式, 在保持紧致遗传算 法快速收玫特性的前提下, 扩展了种群中个体的多样性, 增强了算法进化活力。为减少生产阻塞和降低准备时间对排产过程 的影响, 设计了多种局部启发式规则来指导工件进出多序列有限缓冲区的分配和选择过程。采用某客车制造企业中的实例数 据进行测试, 测试结果表明, 改进的紧致遗传算法与局部指派规则配合使用, 能够有效解决带准备时间的柔性流水车间多序 列有限缓冲区排产优化问题。
\end{abstract}

关键词：柔性流水车间；多序列有限缓冲区；高斯映射；改进的紧致遗传算法

中图分类号: TH186

\section{Multi-queue Limited Buffer Scheduling Problems in Flexible Flow Shop with Setup Times}

HAN Zhonghua 1, 2,3,4 ZHANG Quan ${ }^{2}$ SHI Haibo ZH, 3, $^{\text {ZHANG Jingyuan }}{ }^{2}$

(1. Shenyang Institute of Automation, Chinese Academy of Sciences, Shenyang 110016;

2. Faculty of Information and Control Engineering, Shenyang Jianzhu University, Shenyang 110168;

3. Key Laboratory of Network Control System, Chinese Academy of Sciences, Shenyang 110016; 4. Institutes for Robotics and Intelligent Manufacturing, Chinese Academy of Sciences, Shenyang 110016)

\begin{abstract}
Aiming at solving the multi-queue limited buffer scheduling problems in flexible flow shop with setup times, an improved compact genetic algorithm(ICGA) with local dispatching rules is proposed. Specifically, the global optimization process adopts ICGA algorithm. In order to overcome the issue of premature convergence of compact genetic algorithm (CGA), a Gaussian-mapping-based probabilistic updating method is proposed. Under the premise of maintaining the fast search feature of CGA, ICGA algorithm expand the diversity of population individuals and enhance the evolutionary vigor of the algorithm. In order to reduce the impact of production blocking and setup times on the scheduling process, multiple local heuristic rules are designed to guide the distribution and selection process of the jobs into and out of the multi-queue limited buffer. The instance data in a bus manufacturing enterprise is used for testing. The test results show that the ICGA algorithm combined with local dispatching rules can effectively solve the problem of multi-queue limited buffer scheduling problems in flexible flow shop with setup times.
\end{abstract}

Key words: flexible flow shop; multi-queue limited buffer; Gaussian mapping; improved compact genetic algorithm

* 国家自然科学基金(61873174)、辽宁省重点研发计划指导计划 (2018106008)、辽宁省高等学校基本科研(LJ2017015)和沈阳市科技计划 双百工程(Z18-5-015)资助项目。20180816 收到初稿, 20190328 收到修 改稿 


\section{0 前言}

客车制造企业采用客户定制化的生产方式, 每 天投产的生产订单中车型种类繁多, 不同的车型在 同一个工序加工工时也不相同，在承装车间之前的 焊装和涂装生产车间, 具有多工序多并行工位的特 点, 是典型的柔性流水车间。定制化的生产方式带 来客车的加工工时和工艺流程的差异, 并且客车生产 周期较长, 需要大量的缓冲区车位来临时停放等待加 工的客车。又由于客车属于大体积在制品, 客车生产 线上只能设置车位数量有限的缓冲区, 所以客车制造 企业排产优化问题属于柔性流水车间有限缓冲区排 产优化问题的范畴。在实际生产中, 由于焊装车间和 涂装车间生产节拍的差异较大, 在焊装下线的客车车 体需要较大容量的缓冲区进行临时停放, 而此阶段客 车车体未安装带发动机的底盘, 只能承载在滑捼上移 动。所以为了便于生产管控和更有效的布设移行机, 将其缓冲区划分成多个车道, 每个车道可以存放多辆 客车车体。车体从车道的一侧进入车道, 由移行机带 动滑捼在车道中移动, 最后移出车道, 在每个车道 中形成一个等待加工序列, 多个车道中同时存在多 个等待加工的序列, 这些等待加工的序列共同构成 了一个多序列有限缓冲区。同时，在涂装车间的生 产过程中如果客车车型和颜色等属性信息与工位生 产的前一个客车的属性信息不同时, 加工工位需要 进行清理和器材调整等工作, 这会导致在基本加工 时间之外增加一个准备时间。因此, 客车制造企业 中存在的这类排产优化问题可以归结为带准备时间 的柔性流水车间多序列有限缓冲区排产优化问题。

受到车间实际物理空间的限制, 有限缓冲区排 产优化问题更契合工程实际需求, 因此近年来该问 题的研究得到越来越多的关注。ZHAO 等 ${ }^{[1]}$ 提出具 有线性减小的干扰项改进的粒子群优化 (LDPSO) 用于有限缓冲区流水车间调度的研究; 针对有限缓 冲区流水线调度问题, 谢展鹏等 ${ }^{[2]}$ 提出一种基于变 邻域搜索策略的 Memetic 算法, 并验证了所提算法 的有效性。PAN 等 ${ }^{[3]}$ 提出一种混合离散差分进化算 法(HDDE), 该算法采用多种邻域解的局部搜索增强 了算法的搜索能力。胡蓉等 ${ }^{[4]}$ 采用一种混合差分进 化算法求解加工时间随机分配的有限缓冲区流水线 调度问题。QING 等 ${ }^{[5]}$ 研究具有有限缓冲区的流水车 间调度问题, 提出一种基于嵌入差分进化算法的两 阶段方法。张培文等 ${ }^{[6]}$ 提出一种混合人工蜂群算法, 该算法与基于 NEH 的带权重的曲线拟合(WPFE)启 发式算法进行结合, 在解决有限缓冲区流水车间调
度问题上具有很好的效果。

随着精益生产方式在现代制造企业中的广泛应 用, 在车间整体生产运作过程中对工时、质量、成 本等方面精准控制的标准不断提高, 由于准备时间 的存在增加了完工工时的不确定性, 提高了编制生 产计划的复杂度, 增加了各生产单元配合协作的难 度, 因此, 近年来带准备时间的排产问题的研究越 来越受到了广泛关注。ZHANG 等 ${ }^{[7]}$ 对带准备时间的 流水车间调度问题进行了研究, 并提出一种改进的 蚁群算法(E-ACO)来解决该问题。SHEN 等 ${ }^{[8]}$ 提出一 种带有邻域函数和多样化结构的禁忌搜索算法, 用 来解决带准备时间的 Job shop 调度问题。TRAN 等 ${ }^{[9]}$ 研究带准备时间的同质并行机调度问题, 提出一种分 支检验分解方法。钟涛等 ${ }^{[10]}$ 以最小化总延迟为优化目 标, 提出一种混合进化算法用于求解带准备时间的单 机调度问题。BENKALAI 等 ${ }^{[11]}$ 研究并行工位的置换 流水车间排产优化问题, 并考虑了准备时间的存在, 提出了一种改进的候鸟算法解决该问题。PAN 等 ${ }^{[12]}$ 设计三种局部搜索算法和三种基于种群的启发式方 法对带准备时间的 Job shop 调度问题进行了求解。AN 等 ${ }^{[13]}$ 研究带准备时间和有限等待时间约束的两机 调度问题，并提出一种分支定界算法解决该问题。

通过对近年来相关研究文献的分析可以看出, 目前对于有限缓冲区排产优化问题的研究主要集中 于给定缓冲区容量下的生产车间排产优化问题, 并 侧重于对全局优化算法的研究。通过改进算法或是 将其于不同的算法结合，使得算法在寻优方面更加 精确, 但是少有学者对不同类型的有限缓冲区的排 产优化问题进行系统的研究, 也未针对不同类型的 缓冲区制定相应的局部调度规则。对于带准备时间 的排产优化问题的研究则主要集中于单一属性变化 对准备时间的影响, 研究重点仍侧重于对优化算法 的改进, 而少有学者研究多种属性动态组合结果与 准备时间的关系, 也未进一步研究多种生产约束并 存的情况下的带准备时间的排产优化问题。带准备 时间的柔性流水车间多序列有限缓冲区排产优化问 题较一般柔性流水车间排产优化问题更加复杂, 其 与以往研究工作的不同之处: 在研究带准备时间的 排产优化问题过程中, 重点分析连续加工工件多种 属性信息的动态变化对准备时间取值的影响; 在研 究多序列有限缓冲区排产问题过程中, 不仅研究了 缓冲区的容量受限所带来的生产阻塞问题, 还探讨 了工件进出多序列缓冲区时入道分配和出道选择的 问题。柔性流水车间排产优化问题已被证明是 NP-Hard 问题 ${ }^{[14]}$, 因此, 带准备时间的柔性流水车 间多序列有限缓冲区排产优化问题也同样具有 
NP-Hard 问题的特征。

随着研究问题的复杂化, 应该进一步探索更有 效率的优化方法, CGA 算法是由 HARIK 提出的一 种分布估计算法 ${ }^{[15]}$, 该算法在计算量和进化速度方 面具有极大的优势，但也存在搜索范围较小，易陷 入局部极值的问题。当前学者主要从多种群和概率 分布的方向进行研究来克服其不足之处 ${ }^{[16-17]}$, 单从 这两种方式上不能明显的提高算法优化效果, 还会 损失 CGA 算法快速搜索的优势。为防止 CGA 进化 算法的早熟, 提高生成新个体的质量和多样性, 从 概率模型和概率模型生成新个体的过程进行研究, 提出一种 ICGA 算法, 通过高斯映射将原概率模型 映射到新的概率模型, 增强该算法进化活力和跃出 局部极值能力, 更好的解决带准备时间的柔性流水 车间多序列有限缓冲区排产优化问题。

\section{1 数学模型}

\section{1 问题描述}

如图 1 所示，本文研究的排产优化问题可以描
述为： $n$ 个工件在车间顺序进行 $m$ 道工序的加工， $m$ 道工序中至少有一道工序包含多个并行工位，每 道工序中工件需选择一个工位进行加工 ${ }^{[18]}$ 。工序间 存在确定容量的缓冲区，完工工件进入缓冲区中等 待进行下一道工序加工。若达到缓冲区的容量上限, 则上一道工序完工工件停留在其加工工位上。此时, 该工位被阻塞，无法加工其他工件，直到缓冲区有 存放空间，工件移入缓冲区，该工位才被释放。在 部分工序的有限缓冲区中，存在多个容量有限的等 待序列, 工件从序列的一侧进入，从另外一侧出队 列。当等待序列达到容量限制时, 也会出现工件被 阻塞在上一道加工工序工位的情况。当工件从缓冲 区进入加工工位时，如果工件与该加工工位前一个 加工的工件的属性信息不一致, 会导致在标准加工 时间之外增加一个准备时间。已知工件在各工序上 的标准加工时间，通过排产优化获得工件在生产过 程中的上线顺序，及其在各工序的准备时间、开工 时间和完工时间，求解更好满足排产优化目标的排 产结果。

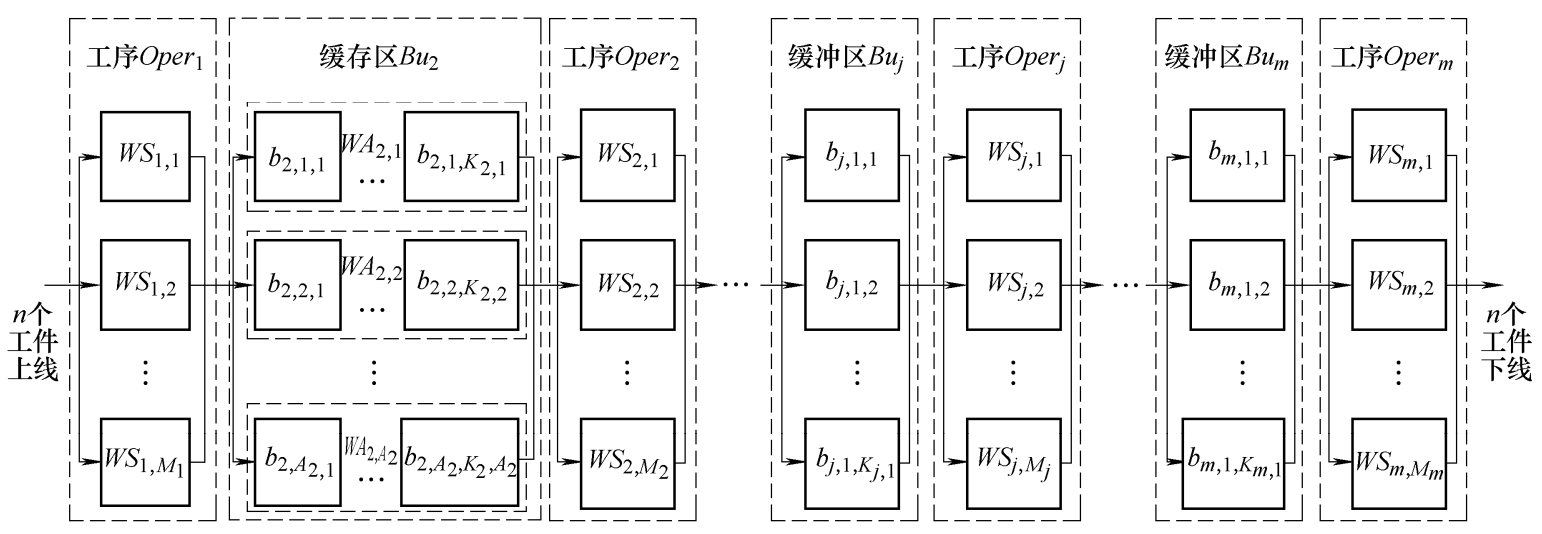

图 1 带准备时间的柔性流水车间多序列有限缓冲区排产优化模型

\section{2 模型参数}

模型参数主要如下。

$n$ : 加工的工件总数;

$m$ : 加工的工序总数;

$B u s_{i}$ 表示第 $i$ 个工件, $i \in\{1, \cdots, n\}$;

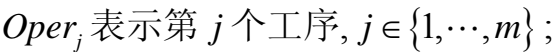

$M_{j}$ 表示工序 $\mathrm{Oper}_{j}$ 中并行机的工位数, $j \in\{1, \cdots, m\}$;

$W S_{j, l}$ 表示工序 Oper $_{j}$ 的第 $l$ 个工位, $j \in\{1, \cdots, m\}$, $l \in\left\{1, \cdots, M_{j}\right\}$;

$B u_{j}$ 表示工序 Oper $_{j}$ 的缓冲区, $j \in\{2, \cdots, m\}$;

$A_{j}$ 表示工序 Oper $_{j}$ 的缓冲区中等待加工队列的个 数, $j \in\{2, \cdots, m\}$;

$B s_{j, a}$ 表示工序 $O p e r{ }_{j}$ 的缓冲区 $B u_{j}$ 中第 $a$ 个序列缓 冲区, $j \in\{2, \cdots, m\}, a \in\left\{1, \cdots, A_{j}\right\}$;
$K_{j, a}$ 表示工序 $O p e r_{j}$ 的缓冲区 $B u_{j}$ 中序列缓冲区 $B s_{j, a}$ 的工位数, $j \in\{2, \cdots, m\}, a \in\left\{1, \cdots, A_{j}\right\}$; $b_{j, a, k}$ 表示在缓冲区 $B u_{j}$ 的序列缓冲区 $B s_{j, a}$ 中第 $k$ 个 缓冲区工位， $j \in\{2, \cdots, m\}, a \in\left\{1, \cdots, A_{j}\right\}$, $k \in\left\{1, \cdots, K_{j, a}\right\}$;

$W A_{j, a}(t)$ 表示在 $t$ 时刻, 缓冲区 $B u_{j}$ 中第 $a$ 个序列缓 冲区 $B s_{j, a}$ 中等待加工工件的队列, $j \in\{2, \cdots, m\}$, $a \in\left\{1, \cdots, A_{j}\right\}$;

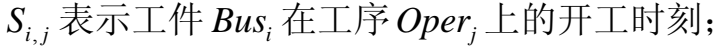

$C_{i, j}$ 表示工件 Bus $s_{i}$ 在工序 Oper $_{j}$ 上的完工时刻;

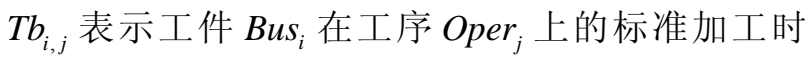
间, $j \in\{1, \cdots, m\}$;

$T e_{i, j}$ 表示工件 $\mathrm{Bus}_{i}$ 进缓冲区 $\mathrm{Bu}$ 的时刻, $j \in\{2, \cdots, m\}$; 
$T l_{i, j}$ 表示工件 $B u s_{i}$ 出缓冲区 $B u_{j}$ 的时刻, $j \in\{2, \cdots, m\}$;

$\mathrm{To}_{i, j}$ 表示工件 Bus ${ }_{i}$ 完成工序 $\mathrm{Oper}_{j}$ 加工后, 移出其 加工工位的时刻, $j \in\{1, \cdots, m\}$;

$T w_{i, j}$ 表示工件 $B u s_{i}$ 在缓冲区 $B u_{j}$ 中等待的时间, $j \in\{2, \cdots, m\}$;

$T s_{i, j, l}$ 表示工件 Bus $s_{i}$ 选择在工位 $W S_{j, l}$ 上加工, 工位 $W S_{j, l}$ 的准备时间, $j \in\{2, \cdots, m\}$;

$N s r v_{x, i, i}^{l}$ 表示工位 $W S_{j, l}$ 上连续加工工件的属性变化 关系, $i, i^{\prime} \in\{1, \cdots, n\}$ 且 $i \neq i^{\prime}$ 。

在排产过程中对于标准有限缓冲区主要关注缓 冲区的容量, 将其作为只包含一个等待队列的缓冲 区, $A_{j}=1$; 多序列有限缓冲区中包含多个序列缓冲 区, 同时, 每个等待加工队列又在一个序列缓冲区 中, 所以等待加工队列的个数等于序列缓冲区的个 数, $A_{j} \geqslant 2$ 。

\section{3 约束条件}

\subsection{1 假设变量}

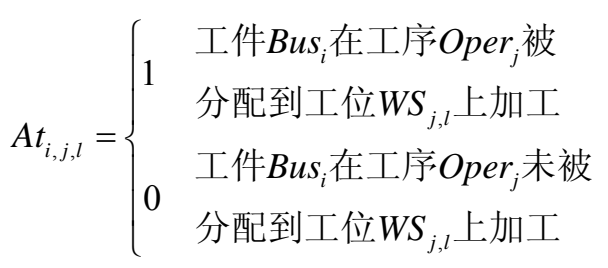

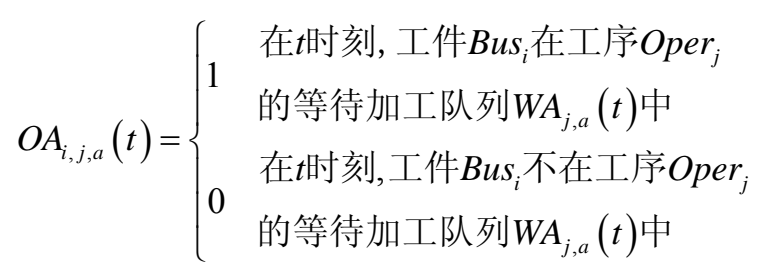

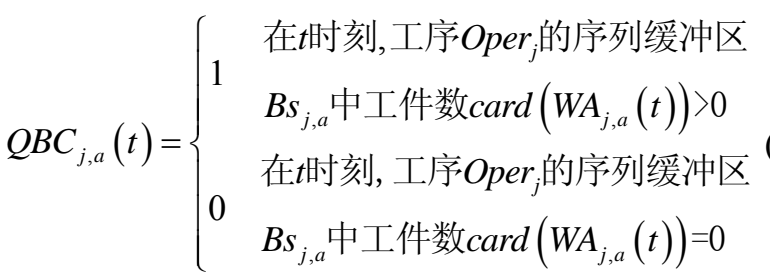

1.3.2 柔性流水车间排产的一般性约束

$$
\begin{gathered}
\sum_{l=1}^{M_{j}} A t_{i, j, l}=1 \\
C_{i, j}=S_{i, j}+T b_{i, j}, i \in\{1,2, \cdots, n\}, j \in\{1,2, \cdots, m\} \\
C_{i, j-1} \leqslant S_{i, j}, i \in\{1,2, \cdots, n\}, j \in\{2,2, \cdots, m\}
\end{gathered}
$$

式(4)表示工件 Bus 在工序 Oper ${ }_{j}$ 上只能在一个 工位上加工的约束, 式(5)表示工件 Bus 在工序 Oper $_{j}$ 上的开工时间与完工时间之间的约束。式(6) 表示工件 Bus $_{i}$ 要进行下一道工序的生产加工过程 之前, 必须先完成当前工序的生产加工。柔性流水 车间的一般性约束对带准备时间的柔性流水车间多
序列有限缓冲区排产优化问题依旧成立。

\subsection{3 有限缓冲区约束}

$$
T o_{i, j}=\left\{\begin{array}{cc}
T e_{i, j+1} & i=\{1, \cdots, m-1\} \\
C_{i, j} & i=m
\end{array}\right.
$$

式(7)表示当工件在工序 $\left(\right.$ Oper $_{j}(i=\{1, \cdots, m-1\})$ 时, 工件离开工位的时刻等于其进入下一道工序缓 冲区的时刻, 当工件在工序 Oper $_{m}$ 时, 工件离开加 工工位的时间等于完工时刻。

$$
T e_{i, j} \geqslant C_{i, j-1}, j \in\{2, \cdots, m\}
$$

式(8)表示工件进入缓冲区的时间要大于等于 工件在上一道工序的完工时刻, 如果有限缓冲区出 现阻塞的情况，工件在上一道工序加工完成后被滞 留在加工工位上。

$$
W A_{j, a}(t)=\left\{B u s_{i} \mid O A_{i, j, a}(t)=1\right\}
$$

式(9)表示在 $t$ 时刻, 有限缓冲区的等待加工队 列中包含的全部工件。

$$
\operatorname{card}\left(W A_{j, a}(t)\right) \leqslant K_{j, a}
$$

式(10)表示, 在任意时刻, 等待加工队列 $W A_{j, a}$ 中包含的工件数要小于等于 $W A_{j, a}$ 所属的序列缓冲 区的最大工位数 $K_{j, a}$ 。

\subsection{4 多序列有限缓冲区约束}

在有限缓冲区约束(8)、(10), 基础上增加两个 新约束(11)、(12)

$$
\sum_{a=1}^{A_{j}} \sum_{i=1}^{n} O A_{i, j, a}(t) \leqslant n
$$

式(11)表示当 $A_{j}>1$ 时, 在任意时刻, 多序列有 限缓冲区的等待加工队列中等待加工的工件总数都 要少于等于工件总数 $n$ 。

$$
\sum_{a=1}^{A_{j}} Q B C_{j, a}(t) \leqslant n
$$

式(12)表示当 $A_{j}>1$ 时, 在任意时刻, 多序 列有限缓冲区中等待加工工件中可进入工序 Oper $_{j}$ 的工位加工的工件总数都要少于等于工件 总数 $n$ 。

如果 $\exists i^{\prime}, i^{\prime \prime} \in\left\{i \mid O A_{i, j, a}(t)=1\right\}, T e_{i, j} \leqslant T e_{i^{\prime \prime}, j}$, 则 $T l_{i^{\prime}, j}$ 和 $T l_{i^{\prime}, j}$ 满足下面关系

$$
T l_{i^{\prime}, j} \leqslant T l_{i^{\prime}, j}
$$

式(13)表示当 $A_{j}>1$ 时, 对于第 $a$ 个有限序 列缓冲区中的工件, 要满足在上一道工序完工先 进入缓冲区的等待加工队列的工件, 也要先出缓 冲区。 
1.3.5 带准备时间的约束

$$
\left(\sum_{l=1}^{M_{j}}\left(T s_{i, j, l} \bullet A t_{i, j, l}\right)+C_{i, j-1}\right) \leqslant S_{i, j}, j \in\{2, \cdots, m\}
$$

式(14)对柔性流水车间基本约束式(6)的扩展, 得 到准备时间与开工时刻和完工时刻的关系, 式(14)表 明本工序开工时刻大于等于上一道工序完工时刻加 上准备时间。

$X$ 表示工件的属性信息的总数, $\operatorname{prop}_{x, i}$ 表示工 件 $\operatorname{Bus}_{i}(i \in\{1, \cdots, n\})$ 的属性, $\operatorname{Prop}_{i}=\left\{\operatorname{prop}_{x, i}\right\}$ 表示工 件 $\operatorname{Bus}_{i}(i \in\{1, \cdots, n\})$ 的属性集合，其中 $x \in\{1, \cdots, X\}$ 。

$$
\operatorname{Nsrv}_{x, i, i}^{l}= \begin{cases}1 & \text { porp }_{x, i} \neq \text { porp }_{x, i} \\ 0 & \text { porp }_{x, i}=\operatorname{porp}_{x, i}\end{cases}
$$

式(15)表示 Bus ${ }_{i}$ 和 Bus $s_{i}^{\prime}\left(i^{\prime}, i^{\prime \prime} \in\{1, \cdots, n\}\right)$ 是工位 $W S_{j, l}$ 上两个连续加工的工件, $\operatorname{Nsrv}_{x, i, i}^{l}=0$, 表示 当两个工件示当两个工件的属性 $\operatorname{prop}_{x, i}$ 和 $\operatorname{prop}_{x, i}$ 相同时, 工位加工后一个工件时不需要准备时 间; $N s r v_{x, i, i}^{l}=1$, 表示当两个工件的属性 $\operatorname{prop}_{x, i}$ 和 $\operatorname{prop}_{x, i}$ 不同时, 工位加工后一个工件需要准备 时间。

$$
T s_{i, j, l}=\sum_{x=1}^{X} T s p_{j, x} \cdot N s r v_{x, i, i^{\prime \prime}}^{l}, \quad j \in\{2, \cdots, m\}
$$

式(16)中, $T s p_{j, x}$ 表示在工序 $O p e r_{j}$ 上连续加工 的两个工件的某一个属性 prop $_{x, i}$ 改变时, 所需的准 备时间。 $T S P_{j}=\left\{T s p_{j, x}\right\}$ 表示在工序 Oper $_{j}$ 上连续加 工的两个工件的属性改变时, 准备时间的集合, 其 中 $x \in\{1, \cdots, X\} 。 T s_{i, j, l}$ 表示当工件 Bus $s_{i}$ 在工序 Oper $_{j}$ 的工位 $W S_{j, l}$ 上加工且与该工位上前一个加工的工 件有多个属性信息不同时, 所需的准备时间。

其他约束条件如下: 不可中断约束: 若工件在 加工工位上已开工, 则不能中断, 直到完成在该工 位的生产过程。工位可用性约束: 排产任务中的工 序包含的所有工位在生产时刻都是可使用的。时间 简化约束: 不考虑工件在序列缓冲区工位之间的转 移时间, 工件在前后工序的加工工位之间的转移时 间, 即在生成调度结果时只需要考虑工件在每个工 序的加工时间和在工位上先后加工的工件属性改变 时增加的准备时间。

\section{4 排产结果评价指标}

(1) 最大完工时间

$$
C_{\max }=\max \left\{C_{i, m}\right\}, \quad i \in\{1,2, \cdots, n\}
$$

式(17)中 $C_{\text {max }}$ 表示全部工件在最后一道工序 加工完工时间中最大值, 也是全部工件完成加工 的时间。
(2) 总工件等待加工时间

$$
T W I P=\sum_{j=2}^{m} \sum_{i=1}^{n}\left(S_{i j}-C_{i, j-1}\right)
$$

式(18) 中工件等待时间是工件 Bus 在工序 Oper $r_{j-1}$ 完工时刻 $C_{i, j-1}$ 到其下道工序 $O p e r_{j}$ 开工时刻 $S_{i j}$ 之间的等待时间, TWIP 表示所有工件在完整的 加工过程中的等待时间之和。在有限缓冲区生产车 间，每个工件在每个工序间的等待时间等于工件在 缓冲区的时间 $T w_{i, j}=T l_{i, j}-T e_{i, j}$ 和工件在加工工位上 的阻塞时间 $T e_{i, j}-C_{i, j-1}$ 与准备时间 $\sum_{l=1}^{M_{j}}\left(T s_{i, j, l} \cdot A t_{i, j, l}\right)$ 之和。

(3) 总工位加工空闲时间

$$
\begin{gathered}
T W T=\sum_{j=1}^{m} \sum_{l=1}^{M_{j}}\left[\left(\max \left\{T o_{i, j} \cdot A t_{i, j, l}\right\}-\min \left\{S_{i, j} \bullet A t_{i, j, l}\right\}\right)-\right. \\
\left.\sum_{i=1}^{n}\left(T b_{i, j} \bullet A t_{i, j, l}\right)\right]
\end{gathered}
$$

式(19)中工位加工空闲时间表示每个工位最早 加工工件的开工时刻到最后加工工件离开该工位的 时刻之间, 加工工位的空闲时间。TWT 表示全部工 位的加工空闲时间之和。

（4）总负荷平衡代价

$$
\overline{T B}_{j}=\left(\frac{\sum_{l=1}^{M_{j}} \sum_{i=1}^{n}\left(T b_{i, j} \cdot A t_{i, j, l}\right)}{M_{j}}\right)
$$

式(20)中 $\overline{T B_{j}}$ 表示在工序 Oper $_{j}$ 的 $M_{j}$ 个并行机 上平均加工时间。

$$
T L B=\sum_{j=1}^{m} \sqrt{\sum_{l=1}^{M_{j}}\left[\sum_{i=1}^{n}\left(T b_{i, j} \cdot A t_{i, j, l}\right)-\overline{T B_{j}}\right]^{2}}
$$

式(21)通过在工序 Oper $_{j}$ 的每一个工位 $W S_{j, l}$ 上 的总加工时间与该工序的并行机平均加工时间 $\overline{T B_{j}}$ 的差值平方后再求和, 建立负荷平衡代价 $T l b_{j}$, 总负 荷平衡代价 $T L B$ 是全部工序的负荷平衡代价之和。

(5) 总设备利用率

$$
F U R=\frac{\sum_{j=1}^{m} \sum_{i=1}^{n}\left(T b_{i, j}\right)}{\sum_{j=1}^{m} \sum_{l=1}^{M_{j}}\left(\max \left\{T o_{i, j} \bullet A t_{i, j, l}\right\}-\min \left\{S_{i, j} \bullet A t_{i, j, l}\right\}\right)}
$$

式(22)中 FUR 表示的柔性流水车间中所有工位 的总设备利用率, 是全部工位有效加工时间与工位 被占用时间跨度之比, 这个时间跨度从工位开始加 工第一个工件到最后一个工件完成加工并离开该工 
位之间的时间跨度, 是一个时间段。

(6) 总工位准备时间

$$
T S=\sum_{i=1}^{n} \sum_{j=1}^{m} \sum_{l=1}^{M_{j}}\left(T s_{i, j, l} \bullet A t_{i, j, l}\right)
$$

式(23)中 TS 表示的柔性流水车间中所有工位的准 备时间之和。

（7）总工件阻塞时间

$$
T P B=\sum_{i=1}^{n} \sum_{j=2}^{m}\left(T e_{i, j}-C_{i, j-1}\right)
$$

式(24)中 TPB 表示的柔性流水车间中所有工件在加 工完成后, 由于缓冲区已满, 阻塞在加工工位的阻 塞时间之和。

\section{2 改进的紧致遗传算法}

在标准紧致遗传算法(CGA)每代进化中, 依据 概率模型的概率分布产生新个体, 再从中选择符合 进化趋势的个体来更新概率模型中的分布概率。概 率模型中的元素, 即模型中的概率值代表了可行解 的分布状况, 在进化过程中不断累计的寻优信息会 在概率模型的概率值中体现。正是由于 CGA 算法 每代采用单一个体更新概率模型, 并且每代进化生 产的新个体也产生于概率模型, 经过几代进化后, 如果控制生成个体基因片段的概率模型中一列(或 是一行)的概率值中有一个过大, 则会导致在以后的 进化过程中生成的新个体中相同位置的基因片段出 现相似的基因, 进而导致概率模型产生新个体的多 样性下降, 又由于从概率模型生成的个体反过来会 更新概率模型, 所以会更加增大概率模型中概率值。 当概率模型中元素(概率值)都变 0 或是 1 的时候, CGA 算法就会终止进化过程。因此一旦进入局部极 值, CGA 算法很难跳出局部极值, 整体进化趋势呈 现不可逆的状态, 导致算法早熟收玫。所以单从扩 大概率模型生产新个体的数量角度考虑, 不能明显 的提高算法优化效果, 还会损失 CGA 算法快速搜 索的优势。

为防止 CGA 进化算法的早熟, 提高生成新个 体的质量和多样性, 应该从概率模型和概率模型生 成新个体的过程进行研究。先判断概率模型中与生 产新个体基因片段相关的一列(或是一行)中概率值 的分布状况, 再通过引入高斯映射来将原概率模型 映射到一个新的概率模型中。在保持原概率模型中 概率值分布关系不变的前提下, 扩展可行解的搜索 能力, 从而扩展概率模型生成新个体的多样性。

\section{1 建立并初始化概率模型}

概率模型用于统计和记录算法每代进化后, 个 体中基因的分布情况。根据个体编码信息包含上线 序和工位分配信息两个部分。建立 $n \times n$ 的矩阵 $P^{L}$ 作为 CGA 算法的上线序概率模型来优化排产的上 线序。概率模型中 1 至 $n$ 行对应工件 $B u s_{1}$ 至 $B u s_{i}, 1$ 至 $n$ 列对应个体的 1 至 $n$ 位, $P_{i, s}^{1}$ 表示工件 $B u s_{i}$ 在上 线加工队列中位置 $s$ 上出现的概率。

概率模型的初始化方式采用均匀分配方式，该 方式直接设置各个位置上每个工件出现的概率均相 等, 其能为算法提供一个较为均衡的优化起点, 采 用均匀分配的方式初始化概率模型 $P$, 即 $\forall(i, s), P_{i, s}^{1}=1 / n$, 有助于扩大算法可行解搜索范围; 并受约束条件 $\forall(\mathrm{s}), \sum_{i=1}^{n} P_{i, s}^{1}=1$ 的限制。

\section{2 增加高斯函数映射的 CGA 算法}

在文献[19]中采用信息熵来评估概率模型中概 率值的分布状态，这种方法对概率值分布状态不是 非常敏感, 本文采用求取概率模型中概率值标准差 的方法, 来评估原概率模型的概率分布, 进而判断 和评估出当前模型搜索可行解的能力。

通过判断原概率模型中概率值的分布状态的结 果, 再将原概率模型 $P^{L}$ 映射到新的高斯概率模型 $F^{L}$, 然后根据高斯概率模型 $F^{L}$ 产生问题的新可行 解 $I^{L}$ (新个体), 再通过新的可行解更新原概率模型 $P^{L}$ 。通过扩展概率模型 $P^{L}$ 选择新的可行解的能力, 增强其搜索可行解的范围。

改进的紧致遗传算法包括 3 个模型, 概率模 型 $P^{L}$ 、概率模型 $F^{L}$ 和模型 $\sigma^{L}$, 概率模型中元素 $P_{i, s}^{L}$ 表示工件 $B u s_{i}$ 在上线加工队列中位置 $s$ 上出现 的概率。

在高斯概率密度函数的参数 $\mu$ 和 $\sigma$ 中, 均值 $\mu$ 决定正态曲线的中心位置; 标准差 $\sigma$ 决定正态曲线 的陡峭或扁平程度。

$$
\mu_{i, s}^{L}= \begin{cases}\sum_{s^{\prime}=1}^{s-1} P_{i, s^{\prime}}^{L}+\frac{P_{i, s}^{L}}{2} & s>1 \\ \frac{P_{i, s}^{L}}{2} & s=1\end{cases}
$$

式中, $\mu_{i, s}^{L}$ 取第 $L$ 代轮盘奢选择的概率模型 $P^{L}$ 中概 率值 $P_{i, s}^{L}$ 的中心值与前 $s-1$ 概率值之和。

$\sigma_{s}^{L}$ 是第 $L$ 代概率模型 $P^{L}$ 中第 $s$ 列元素 $P_{i, s}^{L}$ 的标 准差, 作为高斯概率函数的参数, 参与映射过程。同 时设置基于标准差的启动映射运算的阈值 $\sigma^{T}$ 用以判 断是否启动高斯概率函数将原概率模型映射到新模 型中, 当 $\sigma_{s}{ }^{L}>\sigma^{T}$ 时, 启动高斯概率函数的映射。 
由于进化开始的时候 $P_{i, s}^{L}=1 / n$, 又由于 $\sum_{i=1}^{n} P_{i, s}^{1}=1$, 建立概率模型中一列的标准差 $\sigma_{s}^{L}$, 如式(26)所示, $\sigma_{s}^{L}$ 初始值为 0 。如果 $\sigma_{s}^{L}$ 的值偏小, 高斯概率曲线 将过于陡峭, 影射空间寻优空间过小, 所以增加标准 差调整参数 $\xi$ 到式(26)中, 得到式(27)。

$$
\begin{gathered}
\sigma_{s}^{L}=\sqrt{\frac{1}{n} \cdot \sum_{s=1}^{n}\left(P_{i, s}^{L}-\frac{1}{n}\right)^{2}} \\
\sigma_{s}^{L}=\xi \cdot \sqrt{\frac{1}{n} \cdot \sum_{s=1}^{n}\left(P_{i, s}^{L}-\frac{1}{n}\right)^{2}} \\
\sigma_{s}^{L}=\frac{n \cdot \max \left\{P_{i, s}^{L}\right\}}{\sum_{i=1}^{n} P_{i, s}^{L}-\max \left\{P_{i, s}^{L}\right\}}
\end{gathered}
$$

式(28)中标准差调整参数 $\xi$ 满足约束条件: 当 $\max \left\{P_{i, s}^{L}\right\}=1$ 或 是 $\left(\sum_{i=1}^{n} P_{i, s}^{L}-\max \left\{P_{i, s}^{L}\right\}\right)=0$ 时, $\xi=\sqrt{n}$ 。

$$
f\left(x \mid \mu_{i, s}^{L}, \sigma_{s}^{L}\right)=\frac{1}{\sigma_{s}^{L} \cdot \sqrt{2 \pi}} \exp \frac{\left(x-\mu_{i, s}^{L}\right)^{2}}{2 \sigma_{s}^{L 2}}
$$

式(29)是高斯概率函数, 其中 $\sigma$ 越小, 曲线越 陡峭; $\sigma$ 越大, 曲线越扁平。随着 CGA 算法的进 化, 概率模型中概率值分布性下降, $\sigma$ 的值会变大 (一个概率值占优, 其他概率值很小, 远离均值), 映射后扩展的选择范围也会变大。

将概率模型 $P^{L}$ 中概率值 $P_{i, s}^{L}$ 代入式(26)得到通 过高斯概率映射的新概率模型 $P^{L}$, 然后再次采用轮 盘奢的方式根据新概率模型 $P^{L}$ 选择工件被安排加 工队列中位置, 从而产生更加多样性的新个体。然 后在产生的新个体中, 选择优秀的个体, 再通过这 个优秀的个体通过式(30)更新原概率模型 $P^{L}$ 。

$$
P_{i, s}^{L+1}=\left(1-\frac{\beta}{n}\right) \cdot P_{i, s}^{L}+\frac{\beta}{n} \cdot S t, S t\left\{\begin{array}{l}
1 \text { Gere }_{s}=i \\
0 \text { Gere }_{s} \neq i
\end{array}\right.
$$

式(30)中 $S t$ 是学习系数, $n$ 是加工的工件总数, $\beta$ 是学习速率的调整倍率。每一代选择优秀个体更 新概率模型, 个体中基因值 $G e n e_{s}$, 表示工件 Bus 加 工上线队列中顺序位置。式(30)表示当基因值Genes

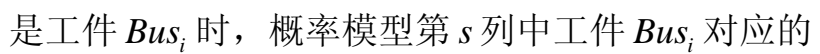
概率值 $P_{i, s}^{1}$ 加上学习系数 $S t$, 进一步增大工件 Bus 被选中在加工上线队列中位置 $s$ 上加工的概率, 该 列中的其他概率值减去 $\frac{\beta}{n} \cdot P_{i, s}^{L}$ 。

\section{3 新个体的解码和编码}

根据概率模型生成 $N P$ 个新个体, 每个新个体的
生成过程: 在 $P^{l}$ 概率模型部分, 个体的第 1 位至第 $n$ 位基因值是根据工件 Bus 在第 $s$ 位上出现的概率 为 $P_{i, s}$, 依次采用轮盘奢的方式选择工件编号, 即工 件上线顺序。

在个体解码过程中, 个体的基因值解码为 $n$ 个 工件在第一道工序的上线加工顺序。工件在每道工 序的一个工位上进行加工过程受到局部调度规则控 制, 由于各道工序间存在有限缓冲区, 当工件进入 缓冲区时, 局部调度规则采用最大序列缓冲区剩余 容量优先规则(Max queue buffer capacity remaining, $\mathrm{MQBCR}$ ); 当工件离开缓冲区, 进入加工工位时, 局部调度规则采用最小准备时间优先规则(Shortest setup time, SST)、最先空闲机器优先规则 (First available machine, FAM)和最早进入排序集合的工 件优先规则(First come first served, FCFS), 其中最 小准备时间优先规则(SST)优先级最高。若下一道工 序的工位都处于加工状态, 并且缓冲区已满, 则该 工件被阻塞在当前加工工位上。在这种情况下，该 工位无法加工其他工件, 直到缓冲区有存放空间, 工件移入缓冲区, 该工位才被释放。同时记录下工 件 Bus 在工序 $\mathrm{Oper}_{j}$ 的选择的加工工位, 该工位的 准备时间 $T s_{i, j}$, 加工开工时间 $S_{i, j}$ 和加工完工时间 $C_{i, j}$, 并记录进入缓冲区时间 $T e_{i, j}$ 、离开缓冲区时 间 $T l_{i, j}$ 等信息, 直到所有工件完成全部工序的加工。 2.3.1 工件进入缓冲区的过程

当工件在上一道工序加工完成进入缓冲区时, 根据有限缓冲区的特点分为两种类型, 对于标准有 限缓冲区, 如果缓冲区存在空闲工位, 即 $\operatorname{card}\left(W A_{j, a}(t)\right)<K_{j, a}$, 则工件直接进入缓冲区等待 序列; 对于多序列有限缓冲区, 上一道工序加工完 成的工件, 依据 MQBCR 规则, 进入下一道序列缓 冲区的等待加工序列中。

$$
\begin{gathered}
\text { 当 } \exists C_{i, j-1} \text { 且 } t=C_{i, j-1} \text { 时, } \\
\operatorname{Mca}_{i, j}(t)=\left\{B s_{j, a} \mid \max \left\{\left[K_{j, a}-\operatorname{card}\left(W A_{j, a}(t)\right) \mid\left(K_{j, a}-\right.\right.\right.\right. \\
\left.\left.\left.\left.\operatorname{card}\left(W A_{j, a}(t)\right)>0\right)\right]\right\}\right\}, j \in\{2, \cdots, m\}
\end{gathered}
$$

式(31)中 $\mathrm{Mca}_{i, j}(t)$ 表示完成上一道工序 $O p e r_{j-1}$ 加工的工件 Bus $s_{i}$ 能够进入的序列缓冲区 $B s_{j, a}$ 的集 合。每个序列缓冲区 $B s_{j, a}$ 的最大工位数 $K_{j, a}$ 与该序 列缓冲区中当前等待加工的工件数量 $\operatorname{card}\left(W A_{j, a}(t)\right)$ 之差是当前该序列缓冲区 $B s_{j, a}$ 的剩 余容量(空闲工位数)。当工件完成上一道工序的加 工, 即 $t=C_{i, j-1}$ 时, 将进入剩余容量最大的序列缓 冲区。当 $\operatorname{card}\left(\mathrm{Mca}_{j}(t)\right)=0$ 时, 表示当前全部序列 
缓冲区都没有剩余容量; 当 $\operatorname{card}\left(M c a_{j}(t)\right)>1$ 时, 表示可以进入多个序列缓冲区。

\subsection{2 工件离开缓冲区的过程}

当工件出缓冲区进入加工工位时, 如果存在 一个工位 $W S_{j, l}$ 空闲, 多个工件在缓冲区中等待的 情况, 即标准有限缓冲区中待加工工件数 $\operatorname{card}\left(W A_{j, a}(t)\right)>1$, 在多序列有限缓冲区中可选择 的待加工工件数 $\sum_{a=1}^{A_{j}} Q B C_{j, a}(t)>1$, 在工件指派工程 中, 首先依据 SST 规则选择其中准备时间最小的工 件 $\left\{B u s_{i} \mid \min \left(T s_{i^{\prime}, j, l}\right)\right\}$ 进行加工。如果准备时间最小 的工件数量大于 2 , 则依据 FIFO 规则选择这些工件 中在缓冲区中等待时间最长的工件 $\left\{B u s_{i} \mid \max \left\{\left(t-T e_{i, j}\right) \mid\left\{i \mid O A_{i, j, a}(t)=1\right\}\right\}\right\}$ 进行加工。如 果存在多个工位空闲, 一个工件等待的情况, 即标 准有限缓冲区中待加工工件数 $\operatorname{card}\left(W A_{j, a}(t)\right)=1$, 在多序列有限缓冲区中可选择的待加工工件数 $\sum_{a=1}^{A_{j}} Q B C_{j, a}(t)=1$, 在工位指派过程中, 先依据 $\mathrm{SST}$ 规则选择准备时间最小的工位进行加工; 如果可选 工位数大于 2 , 则根据 FAM 规则为工件安排工位, 选择最先空闲的工位进行加工。多工位多工件的情 况是上述两类的情况的组合。

\subsection{ICGA 算法流程}

(1) 根据最大熵原则, 初始化概率模型 $P^{L}$ 为: $\forall(i, s) P_{i, s}^{L}=1 / n$, 同时初始化进化代数 $L=0$ 。

以下步骤(2) (5)为通过高斯概率映射到新的 概率模型新个体产生过程。

(2) 采用轮盘奢的方法, 依次根据概率模型 $P^{L}$ 中 各列概率值选择个体中基因采样值(依次为上线队列的 每个位置安排要加工的工件), 一旦某个工件被选中, 该工件随后不再参与选择, 未被选中的工件则继续参 与选择, 直到所有工件安排完毕, 产生一个新个体, 从而生成 $N P$ 个临时新个体 $I_{1}^{\prime}, I_{2}^{\prime}, \cdots, I_{N P}^{\prime}$ 。

(3) 清空高斯概率映射列集合 $F S^{L}$, 计算原概 率模型 $P^{L}$ 中第 $s$ 列的标准差 $\sigma_{s}{ }^{L}$, 判断 $\sigma_{s}{ }^{L}$ 是否大于 启动高斯概率映射的阈值 $\sigma^{T}$, 将符合映射条件的 列 $S^{\prime}$ ，加入高斯概率映射列集合 $F S^{L}$ 。

(4) 通过高斯概率映射列集合 $F S^{L}$ 中列号对应 的原概率模型 $P^{L}$ 中列的概率值和临时新个体 $I_{N p}^{\prime}$ 中 对应的基因值, 计算出来均值 $\mu_{s}{ }^{L}$, 并存入高斯概 率参数 $\mu$ 的集合 $F U^{L}$ 中。

(5) 将原概率模型 $P^{L}$ 属于集合 $F S^{L}$ 中那列的 概率值代入式(29), 通过高斯概率函数建立新概率
模型 $F^{L}$ 。再次采用轮盘奢的方式, 依据新概率模型 $F^{L}$ 中的概率值生成新的基因采样值, 并用这个新值 替换个体 $I_{N p}^{\prime}$ 中对应位置的基因值, 从而生产新的个 体 $I_{N p}$, 转到(4), 直到所有个体处理完成。

(6) 对新生成的 $N P$ 个新个体 $I_{N p}$ 进行解码, 并 求出每新个体的适应度函数值。

(7) 根据适应度函数值选取优秀个体 $I_{\text {best }}$ 引导 概率模型 $P^{L}$ 更新。更新操作根据式(30)进行, 使原 概率模型 $P^{L}$ 在 $I_{\text {best }}$ 引导的方向进化, 更新操作如第 2.2 节所述, 进化代数进行 $L=L+1$ 处理。

(8) 判断更新后的原概率模型 $P^{L+1}$ 是否收玫, 即原概率模型 $P^{L+1}$ 中所有概率值是否为 1 或 0 , 若 符合收玫条件, 则输出历史最优个体, 结束进化过 程, 否则返回(2)继续执行。

\section{3 仿真试验}

算法程序采用 MATLAB 2016a 仿真软件编写, 运行于 Window10 操作系统, 处理器为 Core i5, CPU 为 $1.70 \mathrm{GHz}$, 内存为 $6 \mathrm{~GB}$ 的 PC 机。带准备时间的 柔性流水车间多序列有限缓冲区排产优化问题来源 于客车制造企业的生产实践中，是一类复杂的排产问 题, 其排产结果具有很强的不确定性, 目前缺乏标准 算例。因此, 本文在进行仿真试验时首先采用柔性流 水车间调度问题(Flexible flow shop scheduling problem, FFSP)的标准数据对改进的紧致遗传算法中的参数进 行探讨和分析, 以确定最佳参数值, 并通过多组大规 模和小规模数据测试改进紧致遗传算法对标准紧致 遗传算法寻优能力方面的提升效果。在此基础上, 通 过将多种群体智能算法与多个进出多序列缓冲区的 局部指派规则进行组合, 设计了 8 组对比仿真方案, 并通过带准备时间的柔性流水车间多序列有限缓冲 区的实例数据对 8 组仿真方案进行测试, 进一步分析 ICGA 算法与局部指派规则相结合的方法对于解决此 类问题的效果。

\section{1 算法参数分析}

算法的参数取值对算法的寻优性能有显著的影 响。ICGA 算法中有 3 个关键参数: 启动高斯映射 运算的阈值 $\sigma^{T}$ 、学习速率的调整倍率 $\beta$ 、每一代 生成的新个体数 NP。选择 Carlier 和 Neron 提出的 标准算例对各参数进行测试, 以算例 $\mathrm{j} 15 \mathrm{c} 5 \mathrm{~d} 3$ 为例 说明正交试验的过程。3 个参数各取 4 种水平(表 1) 进行规模为 $\mathrm{L}_{16}\left(4^{3}\right)$ 的正交试验(表 2)。算法在每组试 验中分别运行 20 次, 取其最大完工时间 $C_{\text {max }}$ 的平 均时间 $C_{\max }$ 与进化时间 $T_{\mathrm{cpu}}$ 的平均值 $\overline{T_{\mathrm{cpu}}}$ 作为评价 指标。 
表 1 各参数水平

\begin{tabular}{ccccc}
\hline \multirow{2}{*}{ 参数 } & \multicolumn{3}{c}{ 水平 } \\
\cline { 2 - 5 } & 1 & 2 & 3 & 4 \\
\hline 阈值 $\sigma^{T}$ & 5.0 & 10 & 15 & 20 \\
调整倍率 $\beta$ & 1.0 & 1.5 & 2.0 & 2.5 \\
新个体数 $N P$ & 2.0 & 3.0 & 4.0 & 5.0 \\
\hline
\end{tabular}

表 2 正交试验及试验结果统计表

\begin{tabular}{cccccc}
\hline 试验号 & 阈值 $\sigma^{T}$ & $\begin{array}{c}\text { 调整倍率 } \\
\beta\end{array}$ & $\begin{array}{c}\text { 新个体数 } \\
N P\end{array}$ & $\begin{array}{c}\text { 平均时间 } \\
C_{\max }\end{array}$ & $\begin{array}{c}\text { 进化时间 } \\
T_{\text {cpu }}\end{array}$ \\
\hline 1 & $1(5)$ & $1(1.0)$ & $1(2)$ & 87.70 & 1.219 \\
2 & $1(5)$ & $2(1.5)$ & $2(3)$ & 87.00 & 0.598 \\
3 & $1(5)$ & $3(2.0)$ & $3(4)$ & 87.20 & 0.492 \\
4 & $1(5)$ & $4(2.5)$ & $4(5)$ & 87.30 & 0.406 \\
5 & $2(10)$ & $1(1.0)$ & $2(3)$ & 86.90 & 0.889 \\
6 & $2(10)$ & $2(1.5)$ & $1(2)$ & 87.00 & 0.735 \\
7 & $2(10)$ & $3(2.0)$ & $4(5)$ & 86.80 & 0.573 \\
8 & $2(10)$ & $4(2.5)$ & $3(4)$ & 87.80 & 0.426 \\
9 & $3(15)$ & $1(1.0)$ & $3(4)$ & 86.45 & 1.057 \\
10 & $3(15)$ & $2(1.5)$ & $4(5)$ & 87.35 & 0.687 \\
11 & $3(15)$ & $3(2.0)$ & $1(2)$ & 87.80 & 0.478 \\
12 & $3(15)$ & $4(2.5)$ & $2(3)$ & 87.70 & 0.353 \\
13 & $4(20)$ & $1(1.0)$ & $4(5)$ & 86.70 & 1.116 \\
14 & $4(20)$ & $2(1.5)$ & $3(4)$ & 86.60 & 0.596 \\
15 & $4(20)$ & $3(2.0)$ & $2(3)$ & 87.65 & 0.519 \\
16 & $4(20)$ & $4(2.5)$ & $1(2)$ & 88.45 & 0.338 \\
\hline
\end{tabular}

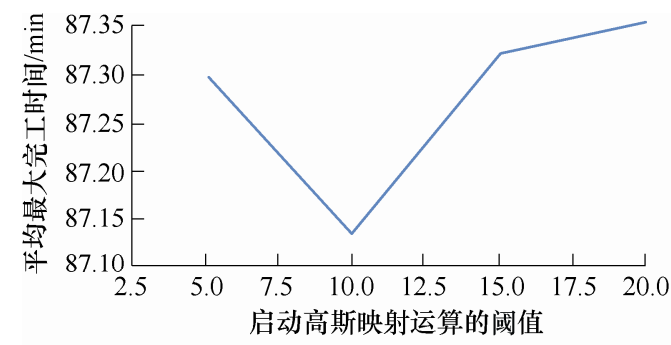

(a1)

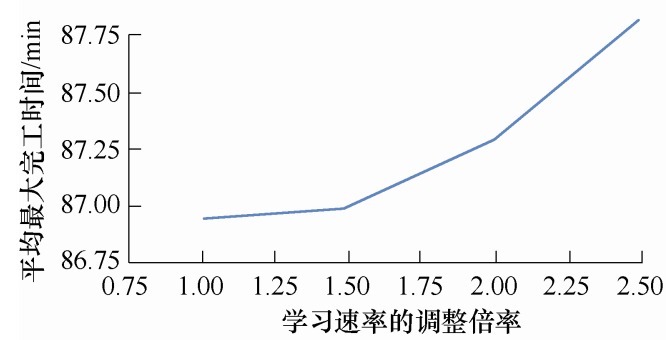

(b1)

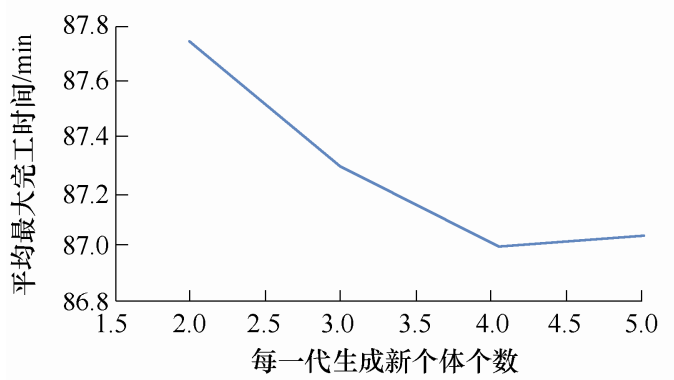

(c1)
表 3 中的 $K_{y}$ 表示各参数在水平 $y$ 上 4 组仿真结 果的平均值。对于每个参数, 如果 $K_{y}$ 越小, 说明 该参数取 $y$ 水平所对应的参数值越好。由计算出的 各参数在各水平下的 $K_{y}$ 值绘制出各参数对算法的 性能趋势图, 如图 2 所示。

\section{表 3 各参数在各水平下正交试验的平均值}

\begin{tabular}{ccccccccc}
\hline \multirow{2}{*}{ 平均值 } & \multicolumn{2}{c}{ 阈值 $\sigma^{T}$} & & \multicolumn{2}{c}{ 调整倍率 $\beta$} & & \multicolumn{2}{c}{ 新个体数 $N P$} \\
& $C_{\max }$ & $T_{\mathrm{cpu}}$ & & $C_{\max }$ & $T_{\mathrm{cpu}}$ & & $C_{\max }$ & $T_{\mathrm{cpu}}$ \\
\hline$K 1$ & 87.30 & 0.679 & & 86.94 & 1.070 & & 87.74 & 0.693 \\
$K 2$ & 87.13 & 0.656 & & 86.99 & 0.654 & & 87.31 & 0.590 \\
$K 3$ & 87.32 & 0.644 & & 87.36 & 0.516 & & 87.01 & 0.643 \\
$K 4$ & 87.35 & 0.642 & & 87.81 & 0.381 & & 87.04 & 0.696 \\
\hline
\end{tabular}

图 2(a1)表明当 $\sigma^{T}$ 取值为 10 时, ICGA 算法得 到最小的 $C_{\text {max }}$ 值。当 $\sigma^{T}$ 小于 10 时会过早的启动高 斯映射破坏了 CGA 算法原有的进化过程使算法无 法得到最好的 $C_{\text {max }}$ 值。同样，当 $\sigma^{T}$ 大于 10 时会导 致高斯映射启动得较晚达不到对 CGA 算法改进的 目的。且如图 2(a2)所示, 随着 $\sigma^{T}$ 的增加 $T_{\mathrm{cpu}}$ 逐渐减 小, 这主要是因为 $\sigma^{T}$ 越大高斯映射启动得越晚。因 此, 设置 $\sigma^{T}=10$ 。

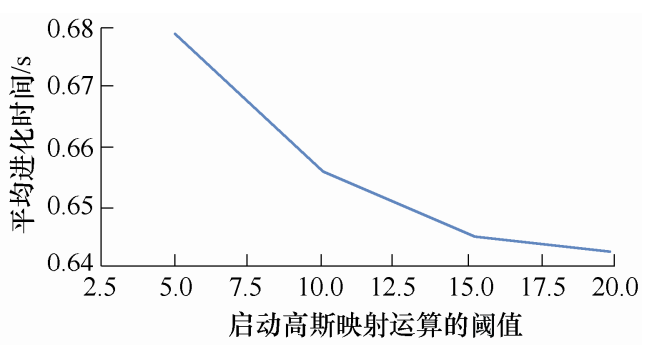

(a2)

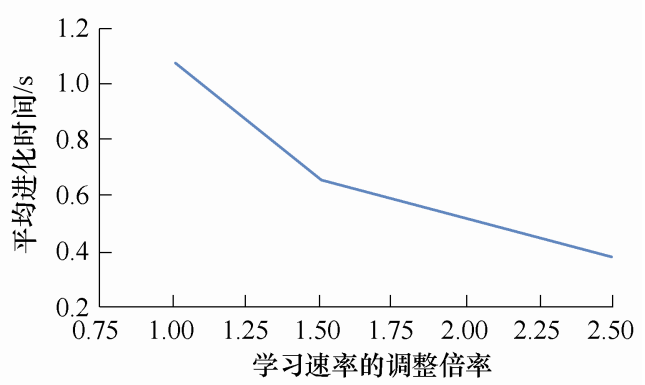

(b2)

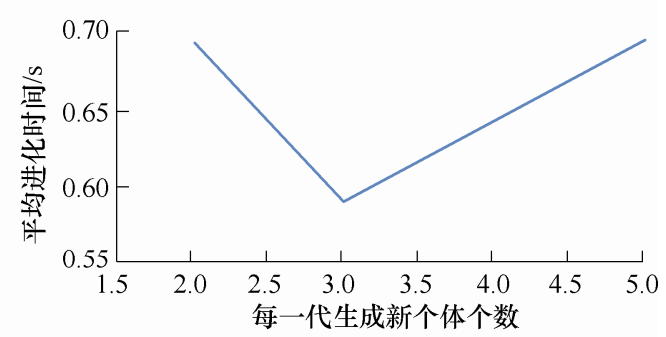

(c2)

图 2 各参数对算法的性能影响趋势图 
由图 2(b1)及图 2(b2)可见 $\beta$ 的取值从 1 到 1.5 的变化过程中, $C_{\max }$ 基本无变化, 但 $T_{\mathrm{cpu}}$ 下降的幅度 非常大。而当 $\beta$ 的取值大于 1.5 以后, $C_{\text {max }}$ 大幅上 升, $T_{\mathrm{cpu}}$ 的下降幅度变小。这表明在 $\beta$ 的取值为 1.5 之前, $\beta$ 的变化对算法的优化效果基本没有影响, 但是随着 $\beta$ 的增大会导致算法的平均进化时间大 幅减小。在 $\beta$ 的取值为 1.5 之后, 随着 $\beta$ 的增加算 法的平均进化时间逐渐减小, 但是算法的优化效果 大大降低, 因此设置 $\beta=1.5$ 。

如图 2(c1) 可见 $N P$ 的取值从 2 到 4 的变化过程 中, $C_{\text {max }}$ 的下降幅度非常大, 在 4 以后的阶段 $C_{\text {max }}$ 趋 于平稳状态。这表明在 $N P$ 的取值为 4 之前, 随着 $N P$ 值的增加, ICGA 算法的优化效果不断提升, 在 4 之后, NP 值的增加对 ICGA 算法的优化效果影响非 常小。如图 2(c2)当 $N P$ 为 3 时算法的平均进化时间 最小。当 $N P$ 小于 3 时随着 $N P$ 的减小 $T_{\mathrm{cpu}}$ 逐渐变大。 这主要是因为算法在每一代生成的新个体数量较 少, 导致算法经过了更多代数的进化才停止。当 $N P$ 大于 3 时随着 $N P$ 的增加, $T_{\mathrm{cpu}}$ 也逐渐变大, 这主要 是因为算法在每一代生成的新个体数量较多, 增加
了算法的计算量导致程序运行的时间成本增加。因 此, 综合考虑算法的平均最大完工时间 $C_{\text {max }}$ 和平均 进化时间 $T_{\mathrm{cpu}}$ 的变化情况, 设置 $N P=4$ 。

\subsection{ICGA 算法优化性能测试}

通过 ICGA 算法、遗传算法 $(G A)$ 、鲸鱼算法 (WOA) 以及标准的紧致遗传算法 (CGA) 在求解 FFSP 的小规模算例和大规模算例中的对比分析, 研 究基于高斯概率模型映射的改进方法对于 CGA 算 法寻优性能的影响。各算法在每组数据下分别运行 30 次, 将平均最大完工时间 $C_{\text {max }}$ 作为主要评价指标, 设置 4 种算法的最大进化代数为 500 代。

\section{2 .1 小规模数据测试}

测试数据来自于 Carlier 和 Neron 针对标准 FFSP 提出的 98 个标准算例, 该算例集分为了 5 种 类型 ${ }^{[20]}$ 。NERSON 在文献[21]中利用分支定界法来 求解该算例集，并依据求解算例的难度将该算例集 分成易解和难解两大类。为了更好地测试 ICGA 算 法对于小规模数据的优化性能, 选取 4 组易解算例 与 4 组难解算例共 8 组数据对 ICGA 算法进行测试。 测试结果如下表所示。

表 4 小规模数据测试结果表

\begin{tabular}{|c|c|c|c|c|c|c|c|c|c|}
\hline \multirow{2}{*}{$\begin{array}{l}\text { 标准 } \\
\text { 算例 }\end{array}$} & \multirow{2}{*}{$L B$} & \multicolumn{2}{|c|}{ GA } & \multicolumn{2}{|c|}{ WOA } & \multicolumn{2}{|c|}{ CGA } & \multicolumn{2}{|c|}{ ICGA } \\
\hline & & $C_{\max }$ & $A R E$ & $C_{\max }$ & $A R E$ & $C_{\max }$ & $A R E$ & $C_{\max }$ & $A R E$ \\
\hline $\mathrm{j} 15 \mathrm{c} 5 \mathrm{a} 1$ & 178 & 178 & 0 & 178 & 0 & 178 & 0 & 178 & 0 \\
\hline $\mathrm{j} 15 \mathrm{c} 5 \mathrm{a} 2$ & 165 & 165 & 0 & 165 & 0 & 165 & 0 & 165 & 0 \\
\hline $\mathrm{j} 15 \mathrm{c} 5 \mathrm{~b} 1$ & 170 & 170 & 0 & 170 & 0 & 170 & 0 & 170 & 0 \\
\hline $\mathrm{j} 15 \mathrm{c} 5 \mathrm{~b} 2$ & 152 & 152 & 0 & 152 & 0 & 152 & 0 & 152 & 0 \\
\hline $\mathrm{j} 15 \mathrm{c} 10 \mathrm{c} 3$ & 141 & 148.67 & $5.44 \%$ & 151 & $7.09 \%$ & 149.03 & $5.7 \%$ & 145.37 & $3.1 \%$ \\
\hline $\mathrm{j} 15 \mathrm{c} 10 \mathrm{c} 4$ & 124 & 133.1 & $7.34 \%$ & 135.87 & $9.57 \%$ & 133.63 & $7.77 \%$ & 131.53 & $6.07 \%$ \\
\hline $\mathrm{j} 15 \mathrm{c} 5 \mathrm{~d} 4$ & 61 & 88.3 & $44.75 \%$ & 89.24 & $46.3 \%$ & 87.17 & $42.9 \%$ & 84.15 & $37.95 \%$ \\
\hline $\mathrm{j} 15 \mathrm{c} 5 \mathrm{~d} 5$ & 67 & 84.53 & $26.16 \%$ & 85.93 & $28.25 \%$ & 82.93 & $23.78 \%$ & 80.23 & $19.75 \%$ \\
\hline
\end{tabular}

表中 $L B$ 表示 Carlier 和 Neron 算例的最大完工 时间的下限(Lower Bound), 其最优值已在文献[22] 中给出, ARE 表示此算法求得的解与最大完工时间 的下限相比较的平均相对误差(Average relative error, $A R E$ ), 可以更好的分析比较各个算法的优化效果。 其计算公式如式(32)所示, ARE 的值越小, 算法的 性能越好。

$$
A R E=\frac{C_{\max }-L B}{L B} \cdot 100 \%
$$

从表中的小规模数据测试结果可知, 对于易解 算例 4 种算法都可以达到该算例的最大完工时间的 下限。对于难解算例而言, GA 算法和 CGA 算法在 前两组数据 $(\mathrm{j} 15 \mathrm{c} 10 \mathrm{c} 3 、 \mathrm{j} 15 \mathrm{c} 10 \mathrm{c} 4)$ 下的平均最大完工 时间 $C_{\text {max }}$ 相差不多, 平均相对误差都比较小, 优化 效果较好。在后两组数据 $(\mathrm{j} 15 \mathrm{c} 5 \mathrm{~d} 4 、 \mathrm{j} 15 \mathrm{c} 5 \mathrm{~d} 5)$ 下, $\mathrm{CGA}$
算法的优化效果要略好于 $\mathrm{GA}$ 算法, 但是平均相对 误差都比较大。与 GA 算法和 CGA 相比, WOA 算 法在 4 组难解算例下的平均相对误差都更大, 优化 效果偏差。ICGA 算法在 4 组难解算例下的平均相 对误差都要比其他 3 种算法更小, 尤其是在最后两 组数据 $(\mathrm{j} 15 \mathrm{c} 5 \mathrm{~d} 4 、 \mathrm{j} 15 \mathrm{c} 5 \mathrm{~d} 5)$ 下的平均相对误差要明显 小于其他 3 种算法。显然, 对于小规模数据的问题, ICGA 算法在寻优性能方面相对于 GA 算法、WOA 算法和 CGA 算法有更好的表现, 尤其对于小规模 数据 $\mathrm{d}$ 类问题的优化效果要明显好于其他几种算 法。这表明 ICGA 算法在解决小规模标准 FFSP 上 具有较好的效果。

\section{2 .2 大规模数据测试}

采用实例规模为 80 个工件 4 道工序、 80 个工 件 8 道工序以及 120 个工件 4 道工序的共 8 组数据, 
来进一步测试 ICGA 算法在求解大规模复杂问题方 面的优化性能。每一个算例中的每一道工序都设置 为包含 3 台并行机, 测试结果如表 5 所示。

\section{表 5 大规模数据测试结果表}

\begin{tabular}{ccccc}
\hline 实例编号 & GA & WOA & CGA & ICGA \\
\hline $\mathrm{j} 80 \mathrm{c} 4 \mathrm{~d} 1$ & 1464.63 & 1485.73 & 1441.53 & 1415.63 \\
$\mathrm{j} 80 \mathrm{c} 4 \mathrm{~d} 2$ & 1363.60 & 1389.8 & 1330.03 & 1307.67 \\
$\mathrm{j} 80 \mathrm{c} 8 \mathrm{~d} 1$ & 1825.70 & 1843.23 & 1799.17 & 1774.07 \\
$\mathrm{j} 80 \mathrm{c} 8 \mathrm{~d} 2$ & 1819.23 & 1839.93 & 1785.43 & 1763.60 \\
$\mathrm{j} 120 \mathrm{c} 4 \mathrm{~d} 1$ & 2136.53 & 2141.93 & 2112.43 & 2094.47 \\
$\mathrm{j} 120 \mathrm{c} 4 \mathrm{~d} 2$ & 2248.43 & 2255.57 & 2217.47 & 2197.77 \\
$\mathrm{j} 120 \mathrm{c} 4 \mathrm{a} 1$ & 2513.63 & 2533.08 & 2480.33 & 2458.23 \\
$\mathrm{j} 120 \mathrm{c} 4 \mathrm{a} 2$ & 2449.33 & 2480.60 & 2415.57 & 2377.54 \\
\hline
\end{tabular}

从表中的测试结果可以看出, ICGA 算法对于 各组大规模数据的优化结果均小于其他 3 种算法。 其中, 对于 $\mathrm{j} 80 \mathrm{c} 4 \mathrm{~d}$ 类问题 ICGA 算法优化结果的平 均值为 1361.65 , GA 算法为 1414.12 , WOA 为 1437.77 , CGA 算法为 1385.78。对于 j80c8d 类问 题 ICGA 算法优化结果的平均值为 1768.84 , GA 算 法为 1822.47 , WOA 为 1841.58 , CGA 算法为 1792.3 。对于 j120c4d 类问题 ICGA 算法优化结果 的平均值为 $2146.12, \mathrm{GA}$ 算法为 2192.48 , WOA 为 2198.75 , CGA 算法为 2164.95 。对于 $\mathrm{j} 120 \mathrm{c} 8 \mathrm{~d}$ 类问题 ICGA 算法优化结果的平均值为 2417.89 , $\mathrm{GA}$ 算法为 2481.48 , WOA 为 $250.84, \mathrm{CGA}$ 算法为 2 447.95。由以上分析得出, 对于处理大规模数据的 优化问题, ICGA 算法的效果要好于 GA 算法、WOA 算法以及 CGA 算法。

在进行测试的过程中发现每种算法在大规模的 数据下分别运行 30 次时每次得到的最大完工时间 $C_{\text {max }}$ 相差较大, 有的算法甚至会落入到局部极值中 造成较大的异常值的出现。为了更好地比较和评价 各个算法对于大规模数据的优化效果, 这里以 $\mathrm{j} 80 \mathrm{c} 4 \mathrm{~d} 2$ 组数据为例将 4 种算法在 $\mathrm{j} 80 \mathrm{c} 4 \mathrm{~d} 2$ 组数据下 运行 30 次所得到的适应度值结果绘制成箱形图如图 3 所示。

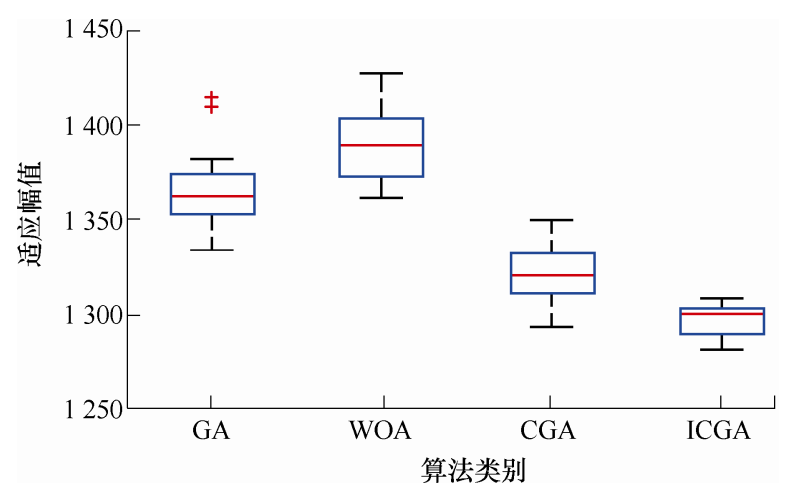

图 3 大规模数据下四种算法箱形图
箱形图(Box-plot)是一种用作显示一组数据离散程 度的统计图, 通过箱形图可以体现出优化效果的稳 定性, 在箱形图种采用四分位距 (IQR) 来衡量数据 的离散程度

从图 3 中可以看出, 在 30 次的运行中 $\mathrm{GA}$ 算法 产生了 2 个较大的异常值, 说明 $\mathrm{GA}$ 算法比较容易 落入局部极值中。ICGA 算法产生的箱形图的位置 最低, 说明 ICGA 算法产生的解的整体质量比其他 3 种算法更好。并且, ICGA 算法产生的箱形图的 $I Q R$ 要比其他 3 种算法产生的箱形图的 IQR 更小, 这说明 ICGA 算法产生的解的离散程度比其他 3 种 算法更小, 其在大规模数据下排产结果的稳定性是 4 种算法中最好的。

通过以上方法采用大小规模的数据分别对 4 种 算法进行测试得出, 在解决标准 FFSP 上, ICGA 算 法比其他 3 种算法具有更强的持续进化和跃出局部 极值的能力, 通过高斯概率模型映射的改进方法能 够扩展 CGA 算法进化过程中解的搜索范围, 在一 定程度上克服了其早熟收敛的问题。

\section{3 带准备时间的柔性流水车间多序列有限缓冲 区实例测试}

\subsection{1 构建仿真数据}

构建贴近客车制造企业的焊装车间和涂装车间 的生产运作情况的仿真数据。

(1) 车间模型参数。某客车制造企业的焊装车 间是由多条生产线构成的刚性流水车间，可以将其 简化为 1 个生产工序, 涂装车间中工序简化为 3 工 序, 排产仿真数据共包含 4 个工序, 即 $\left\{\right.$ Oper $_{1}$, Oper $_{2}$, $\left.\mathrm{Oper}_{3}, \mathrm{Oper}_{4}\right\}, 4$ 个工序的并行工位数 $\left\{M_{j}\right\}$ 为 $\{3,2,3,2\}$ 。焊装车间和涂装车间之间缓冲区是多序 列有限缓冲区, 所以将排产仿真数据中工序 $\mathrm{Oper}_{2}$ 的缓冲区设置为多序列有限缓冲区。工序 Oper $_{2}$ 的 缓冲区 $B u_{2}$ 中序列缓冲区个数 $A_{2}=2$, 其中序列缓冲 区 $B s_{2,1}$ 包含的工位数 $K_{2,1}=2, B s_{2,2}$ 包含的工位数 $K_{2,2}=2$, 即, 多序列有限缓冲区中有 2 个序列缓冲 区, 每个序列缓冲区中有 2 个停放待加工客车车体 的工位。

在涂装车间的生产过程中工位先后加工两辆客 车的车型和颜色属性的改变, 需要对工位进行清洁 和生产设备调整等工作, 所以仿真过程将客车车型 和颜色属性的改变作为计算准备时间的依据。在表 6 中设置工位先后加工的客车车型改变的准时间参 数和先后加工的客车颜色改变时的准备时间参数。 当客车从缓冲区进入下一道工序的加工工位时, 由 式(16)来计算增加的工位准备时间。 


\section{表 6 模型参数表}

\begin{tabular}{|c|c|c|c|}
\hline & 模型参数 & 参数说明 & 参数值 \\
\hline \multirow{6}{*}{$\begin{array}{c}\text { 有限 } \\
\text { 缓冲区 } \\
\text { 相关 } \\
\text { 参数 }\end{array}$} & \multirow[t]{2}{*}{$A_{2}$} & 工序 $\mathrm{Oper}_{2}$ 的缓冲区 $B u_{2}$ 的序列缓冲 & \multirow[t]{2}{*}{2} \\
\hline & & 区个数 & \\
\hline & $K_{2,1}$ & 序列缓冲区 $B s_{2,1}$ 的容量 & 2 \\
\hline & $K_{2,2}$ & 序列缓冲区 $B s_{2,2}$ 的容量 & 2 \\
\hline & $K_{3,1}$ & 工序 $\mathrm{Oper}_{3}$ 有限的缓冲区 $B u_{3}$ 的容量 & 1 \\
\hline & $K_{4,1}$ & 工序 $\mathrm{Oper}_{4}$ 的有限缓冲区 $B u_{4}$ 的容量 & 1 \\
\hline \multirow{12}{*}{$\begin{array}{l}\text { 准备 } \\
\text { 时间 } \\
\text { 相关 } \\
\text { 参数 }\end{array}$} & \multirow{2}{*}{$T s p_{2,1}$} & 在工序 $\mathrm{Oper}_{2}$ 并行工位上, 先后加工的 & \multirow{2}{*}{4} \\
\hline & & 客车车型改变时的准备时间参数 & \\
\hline & \multirow{2}{*}{$T s p_{2,2}$} & 在工序 $\mathrm{Oper}_{2}$ 并行工位上, 先后加工的 & \multirow{2}{*}{4} \\
\hline & & 客车颜色改变时的准备时间参数 & \\
\hline & \multirow{2}{*}{$T s p_{3,1}$} & 在工序 $\mathrm{Oper}_{3}$ 并行工位上, 先后加工的 & \multirow{2}{*}{5} \\
\hline & & 客车车型改变时的准备时间参数 & \\
\hline & \multirow{2}{*}{$T s p_{3,2}$} & 在工序 $\mathrm{Oper}_{3}$ 并行工位上, 先后加工的 & \multirow[b]{2}{*}{5} \\
\hline & & 客车颜色改变时的准备时间参数 & \\
\hline & \multirow{2}{*}{$T s p_{4,1}$} & 在工序 $\mathrm{Oper}_{4}$ 并行工位上, 先后加工的 & \multirow{2}{*}{3} \\
\hline & & 客车车型改变时的准备时间参数 & \\
\hline & \multirow{2}{*}{$T s p_{4,2}$} & 在工序 $\mathrm{Oper}_{4}$ 并行工位上, 先后加工的 & \multirow[b]{2}{*}{3} \\
\hline & & 客车颜色改变时的准备时间参数 & \\
\hline
\end{tabular}

(2) 加工对象参数。客车属性信息的总数 $X=2, \operatorname{Prop}_{1}$ 表示客车的车型属性, Prop $_{2}$ 表示客 车的颜色属性, 车型属性 PropValue ${ }_{1}=\left\{\right.$ BusType $_{1}$, BusType $_{2}$, BusType $\left._{3}\right\}$, 颜色属性PropValue ${ }_{2}=\left\{\right.$ BusColor $_{1}$, BusColor, BusColor $\left._{3}\right\}$, 假设工序 $\mathrm{Oper}_{2}$ 的加工工位 $W S_{2,1}$ 上两个连续加工的客车 $\mathrm{Bus}_{3}, \mathrm{Bus}_{5}$, 如果车 型属性 prop $_{1,3}=$ BusType $_{2}$, prop $_{1,5}=$ BusType $_{2}$, 客车 颜色属性 prop $_{2,3}=$ BusColor $_{3}$, prop $_{2,5}=$ BusColor $_{1}$, 则 $\operatorname{prop}_{1,3}=\operatorname{prop}_{1,5}, \operatorname{prop}_{2,3} \neq \operatorname{prop}_{2,5}$, 得到 $N s r v_{2,3,5}^{2}=1$, 由式(16)计算出准备时间 $T s_{5,2,2}=T s p_{2,2}=4$ 。

表 7 客车的车型和颜色属性信息表

\begin{tabular}{|c|c|c|}
\hline 客车属性 & 车型 Prop $_{1}$ & 颜色 $\mathrm{Prop}_{2}$ \\
\hline $\mathrm{Bus}_{1}$ & Type $_{1}$ & Color $_{1}$ \\
\hline $\mathrm{Bus}_{2}$ & Type $_{2}$ & Color $_{1}$ \\
\hline $\mathrm{Bus}_{3}$ & Type $_{3}$ & Color $_{2}$ \\
\hline $\mathrm{Bus}_{4}$ & Type $_{2}$ & $\mathrm{Color}_{2}$ \\
\hline $\mathrm{Bus}_{5}$ & Type $_{1}$ & $\mathrm{Color}_{3}$ \\
\hline $\mathrm{Bus}_{6}$ & Tyре $_{3}$ & Color $_{3}$ \\
\hline $\mathrm{Bus}_{7}$ & Type $_{1}$ & Color $_{1}$ \\
\hline $\mathrm{Bus}_{8}$ & Type $_{2}$ & Color $_{1}$ \\
\hline $\mathrm{Bus}_{9}$ & Tyре $_{3}$ & Color $_{2}$ \\
\hline Bus $_{10}$ & Type $_{1}$ & Color $_{3}$ \\
\hline Bus $_{11}$ & Type $_{2}$ & Color $_{2}$ \\
\hline Bus $_{12}$ & Type $_{3}$ & $\mathrm{Color}_{3}$ \\
\hline
\end{tabular}

表 8 客车生产的标准加工工时表

\begin{tabular}{lcccc}
\hline & Oper $_{1}$ & Oper $_{2}$ & Oper $_{3}$ & Oper $_{4}$ \\
\hline Bus $_{2}$ & 8 & 30 & 34 & 42 \\
Bus $_{2}$ & 11 & 38 & 38 & 36 \\
Bus $_{3}$ & 15 & 28 & 44 & 26 \\
Bus $_{4}$ & 19 & 25 & 42 & 24 \\
Bus $_{5}$ & 10 & 26 & 52 & 34 \\
Bus $_{6}$ & 16 & 36 & 40 & 30 \\
Bus $_{7}$ & 12 & 20 & 46 & 28 \\
Bus $_{8}$ & 21 & 24 & 48 & 32 \\
Bus $_{9}$ & 22 & 22 & 35 & 38 \\
Bus $_{10}$ & 13 & 32 & 36 & 40 \\
Bus $_{11}$ & 20 & 35 & 45 & 44 \\
Bus $_{12}$ & 14 & 34 & 50 & 22 \\
\hline
\end{tabular}

\subsection{2 仿真方案}

通过将 ICGA 算法、GA 算法、WOA 算法以及标 准的 CGA 算法作为全局优化算法, 并与多个进出多 序列缓冲区的局部指派规则组合运用到求解上述某 客车制造企业的排产优化问题中，进一步分析 ICGA 算法与局部指派规则相结合的方法解决带准备时间 的柔性流水车间多序列有限缓冲区排产问题的效果。 共设计 8 组仿真方案, 仿真方案 1 4 的局部指派规 则为先入先出规则(FIFO), 仿真方案 $5 \sim 8$ 进入序列缓 冲区采用最大序列缓冲区剩余容量优先规则 (MQBCR), 出缓冲区时采用最小准备时间优先规则 (SST)、最先空闲机器优先规则(FAM) 以及最早进入排 序集合的工件优先规则(FCFS)为局部指派规则, 其中 SST 规则优先级最高, 8 组仿真方案信息如表 9 所示。

表 98 组仿真方案信息

\begin{tabular}{ccc}
\hline 仿真方案 & 全局优化算法 & 局部指派规则 \\
\hline 1 & GA & FIFO \\
2 & WOA & FIFO \\
3 & CGA & FIFO \\
4 & ICGA & FIFO \\
5 & GA & MQBCR, SST、FAM、FCFS \\
6 & WOA & MQBCR, SST、FAM、FCFS \\
7 & CGA & MQBCR, SST、FAM、FCFS \\
8 & ICGA & MQBCR, SST、FAM、FCFS \\
\hline
\end{tabular}

\subsection{3 仿真结果与分析}

\subsubsection{1 排产结果评价指标}

在优化过程中采用最大完工时间 $C_{\max }$ 作为全 局优化算法的适应度函数值, 并同时建立与生产线 实际应用相关的多项评价指标，其中包括总工件等 待加工时间 TWIP、总工位加工空闲时间 TWT 、总 负荷平衡代价 $T L B$ 、总设备利用率 FUR 、总工位准 
备时间 TS 和总工件阻塞时间 TPB 。除总设备利用 组仿真方案分别运行 20 次, 并将 20 次仿真结果的 率 FUR 以外其他评价指标值都是越小越优 ${ }^{[23]}$ 。将 8 平均值放入表 10 中。

表 108 组方案排产结果的评价指标对照表

\begin{tabular}{|c|c|c|c|c|c|c|c|c|c|}
\hline \multicolumn{2}{|c|}{ 评价指标 } & 方案 1 & 方案 2 & 方案 3 & 方案 4 & 方案 5 & 方案 6 & 方案 7 & 方案 8 \\
\hline \multirow{3}{*}{$C_{\max }$} & 最优值 & 298 & 299 & 296 & 296 & 294 & 292 & 295 & 288 \\
\hline & 最差值 & 305 & 310 & 304 & 302 & 302 & 302 & 300 & 296 \\
\hline & 平均值 & 302.8 & 303.75 & 301.6 & 299.5 & 298.5 & 298.75 & 297.3 & 292.6 \\
\hline \multirow{3}{*}{ TWIP } & 最优值 & 686 & 650 & 680 & 644 & 656 & 617 & 644 & 627 \\
\hline & 最差值 & 778 & 792 & 744 & 747 & 775 & 746 & 740 & 693 \\
\hline & 平均值 & 719.5 & 711.85 & 708.55 & 700.5 & 711.3 & 680.15 & 689.65 & 660.75 \\
\hline \multirow{3}{*}{ TWT } & 最优值 & 296 & 291 & 282 & 279 & 267 & 244 & 229 & 225 \\
\hline & 最差值 & 385 & 374 & 370 & 359 & 320 & 346 & 337 & 316 \\
\hline & 平均值 & 346.65 & 325.7 & 322 & 311.15 & 300 & 269.7 & 286.1 & 256.65 \\
\hline \multirow{3}{*}{$T L B$} & 最优值 & 43.75 & 41.04 & 44.16 & 41.57 & 40.82 & 28.09 & 26.28 & 28.84 \\
\hline & 最差值 & 102.5 & 110.4 & 101.93 & 97.4 & 74.78 & 92.94 & 80.8 & 84.97 \\
\hline & 平均值 & 66.38 & 63.55 & 64.38 & 63.43 & 55.33 & 53.82 & 53.73 & 53.26 \\
\hline \multirow{3}{*}{ FUR } & 最优值(\%) & 83.12 & 83.56 & 83.35 & 83.70 & 84.32 & 86.05 & 85.30 & 86.46 \\
\hline & 最差值(\%) & 78.06 & 79.46 & 78.86 & 80.32 & 81.48 & 80.33 & 81.24 & 82.15 \\
\hline & 平均值(\%) & 79.33 & 81.18 & 80.71 & 82.28 & 82.68 & 84.12 & 83.35 & 85.36 \\
\hline \multirow{3}{*}{$T S$} & 最优值 & 137 & 131 & 125 & 120 & 131 & 113 & 117 & 110 \\
\hline & 最差值 & 169 & 158 & 162 & 152 & 163 & 147 & 154 & 132 \\
\hline & 平均值 & 149.05 & 139.05 & 142.4 & 132.3 & 139.65 & 129.05 & 133.8 & 122.4 \\
\hline \multirow{3}{*}{ ТРB } & 最优值 & 102 & 90 & 92 & 86 & 93 & 82 & 81 & 74 \\
\hline & 最差值 & 151 & 135 & 131 & 115 & 131 & 120 & 108 & 98 \\
\hline & 平均值 & 124.85 & 112.7 & 108.8 & 99.75 & 108.4 & 99.1 & 95.75 & 87.95 \\
\hline
\end{tabular}

从表 10 可以看出, 与局部指派规则为 FIFO 规则 的方案 1 4 相比, 采用了 MQBCR 规则、SST 规则、 FAM 规则以及 FCFS 规则的方案 5 8 的各个评价指 标都得到了显著的优化。在采用同一种全局优化算法 的前提下, 方案 5 比方案 1 的总工位加工空闲时间减 少了 $13.46 \%$ 、总工位准备时间减少了 $6.31 \%$ 、总工件 阻塞时间减少了 $13.18 \%$ 。方案 6 比方案 2 的总工位 加工空闲时间减少了 $17.19 \%$ 、总工位准备时间减少 了 $9.09 \%$ 、总工件阻塞时间减少了 $12.07 \%$ 。方案 7 比方案 3 的总工位加工空闲时间减少了 $11.15 \%$ 、总 工位准备时间减少了 $6.51 \%$ 、总工件阻塞时间减少了 $11.99 \%$ 。方案 8 比方案 4 的总工位加工空闲时间减少 了 $20.73 \%$ 、总工位准备时间减少了 $8.80 \%$ 、总工件阻 塞时间减少了 $15.14 \%$ 。说明个体解码过程中采用 MQBCR 规则和 SST 规则, 并与优化算法结合, 能够 更加充分利用多序列有限缓冲区容量, 显著减少总工 位加工空闲时间、总工位准备时间和总工件阻塞时 间，从而更有效处理这类复杂的排产问题。

从表 10 中数据分析各优化算法的优化性能, 对 比方案 $1 \sim 4$ 或方案 $5 \sim 8$ 可知, 在两种不同的局部 指派规则下, ICGA 算法对于最大完工时间的优化 效果都是 4 种算法中最好的。从表中可以看出, 采 用 ICGA 算法的方案 4 和方案 8 的总工位加工空闲 时间比采用 $\mathrm{GA}$ 算法的方案 1 和方案 5 分别减少了
$10.24 \%$ 与 $14.45 \%$, 比采用 WOA 算法的方案 2 和方 案 6 分别减少了 $4.47 \%$ 与 $4.84 \%$, 比采用 CGA 算法 的方案 3 和方案 7 分别减少了 $3.37 \%$ 与 $10.29 \%$ 。采 用 ICGA 算法的方案 4 和方案 8 的总工位准备时间 比采用 $\mathrm{GA}$ 算法的方案 1 和方案 5 分别减少了 $11.24 \%$ 与 $12.35 \%$, 比采用 WOA 算法的方案 2 和方 案 6 分别减少了 $4.85 \%$ 与 $5.15 \%$, 比采用 CGA 算法 的方案 3 和方案 7 分别减少了 $7.09 \%$ 与 $8.52 \%$ 。采用 ICGA 算法的方案 4 和方案 8 的总工件阻塞时间比采 用 $\mathrm{GA}$ 算法的方案 1 和方案 5 分别减少了 $20.10 \%$ 与 $18.87 \%$, 比采用 WOA 算法的方案 2 和方案 6 分别减 少了 $11.49 \%$ 与 $11.25 \%$, 比采用 CGA 算法的方案 3 和方案 7 分别减少了 $8.32 \%$ 与 $8.15 \%$ 。与采用其他 3 种算法的方案相比, 采用 ICGA 算法的方案 4 和方案 8 其他评价指标也都获得了不同程度的优化。上述结 果说明当以最大完工时间作为优化目标时, 其他评 价指标也同时获得了优化,这也说明采用 ICGA 算法 能够能更好地减少工位准备时间, 更有效地降低有 限缓冲区带来的阻塞影响, 更合理地安排工件进出 序列缓冲区工位, 更有序地安排加工任务, 从而改 善各项评价指标, 具有更好的寻优性能。

\subsubsection{2 排产结果 Gantt 图分析}

图 4 所示的方案 8 的排产结果的 Gantt 图。图中缓 冲区中的浅灰色表示客车在缓冲区停留时间，工位中的 
浅灰色表示工位前后加工客车属性不同时产生的准备 时间, 工位中的深灰色表示客车加工完成后, 滞留在工 位上的阻塞时间。其中, 客车 Bus 3 所经过的加工路线 为 $\left\{W S_{1,1}, b_{2,2,1}, b_{2,2,2}, W S_{2,2}, b_{3,1,1}, W S_{3,1}, b_{4,1,1}, W S_{4,1}\right\}$, 在 图 4 中可以直观看出在 $t=44$ 时刻, 客车Bus 3 完成工序 Oper . 的工位 $W S_{1,1}$ 上加工(客车 Bus 3 完工时间 $C_{3,1}$ $=44), \quad W A_{2,1}(t)=\left\{\mathrm{Bus}_{8}, \mathrm{Bus}_{4}\right\}, \operatorname{card}\left(W A_{2,1}(t)\right)=2$, $W A_{2,2}(t)=\left\{\right.$ Bus $\left._{9}\right\}, \operatorname{card}\left(W A_{2,2}(t)\right)=1$, 序列缓冲区
$B s_{2,1}$ 的容量 $K_{2,1}=2, \operatorname{card}\left(W A_{2,1}(t)\right) \leqslant K_{2,1}$, 序列缓 冲区 $B s_{2,2}$ 的容量 $K_{2,2}=2, \operatorname{card}\left(W A_{2,2}(t)\right) \leqslant K_{2,2}$, 都满足有限缓冲区约束 $(10)$ 。根据控制工件进入 缓冲区的 MQBCR 规则, 通过式 (28) 得出

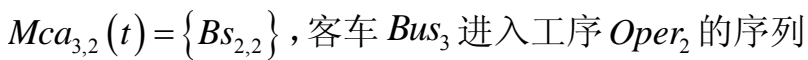
缓冲区 $B s_{2.2}$ 的缓冲区工位 $b_{2,2,1}$, 排队等待进入工序 $\mathrm{Oper}_{2}$ 加工, 客车进入缓冲区时间 $T e_{3,2}=C_{3,1}$, 也满 足有限缓冲区约束 $(8)$ 。

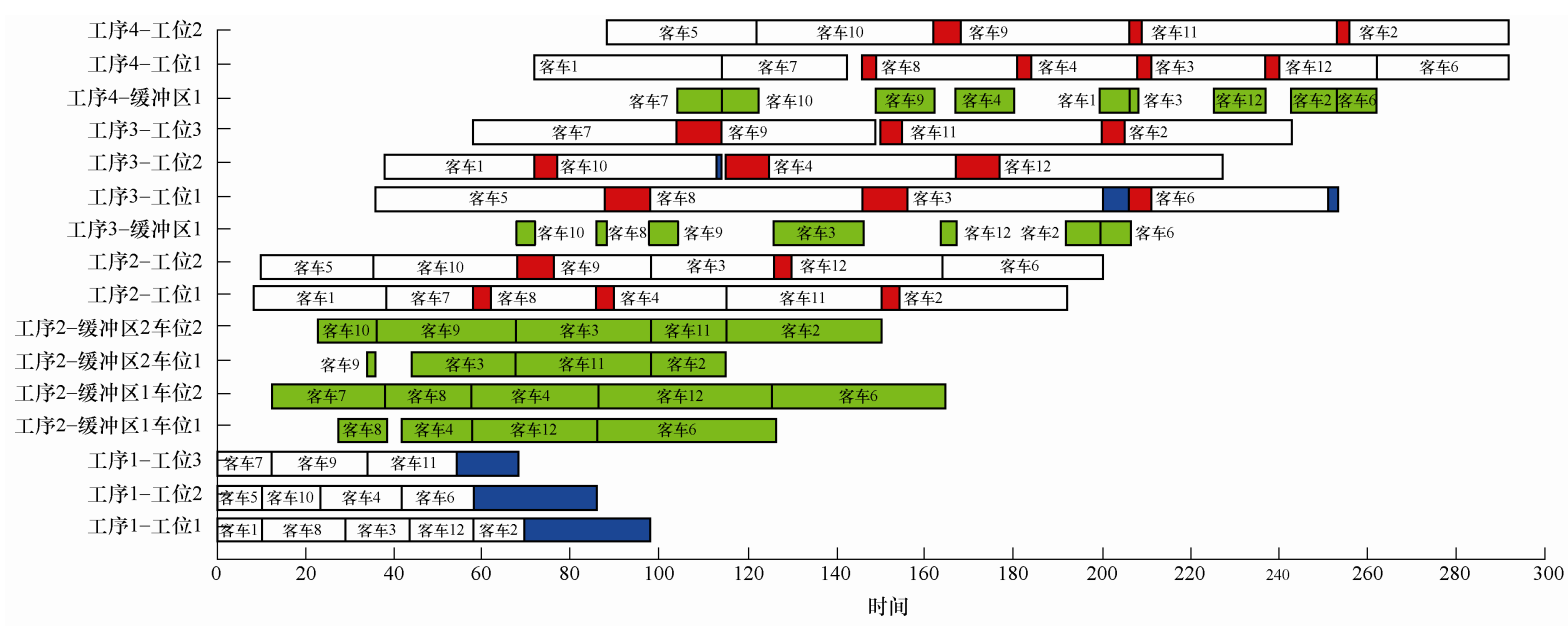

图 4 ICGA 算法排产结果 Gantt 图

在 $t=68$ 时刻, 客车 Bus9 离开序列缓冲区 $B s_{2.2}$ 的缓冲区工位 $b_{2,2,2}$, 离开缓冲区时间 $T l_{9,2}=68$, 同 时在 $t=68$ 时刻, 客车 $B u s_{3}$ 移动到 $B s_{2.2}$ 的缓冲区工 位 $b_{2,2,2}$ 上等待进入工序 Oper $_{2}$ 加工工位。在 $t=98$ 时 刻, $T l_{3,2}=98$, 客车 $B u s_{3}$ 也离开缓冲区, $T l_{9,2}<T l_{3,2}$, 满足多序列缓冲区约束(13)。从 Gantt 图中可以看出 在使用序列缓冲区的过程中始终满足约束(12)。

进一步分析上述过程中客车Bus 3 离开缓冲区过 程, 当 $t=98$ 时刻, 工位 $W S_{2,2}$ 完成客车 $B u s_{9}$ 的加工, 工位 $W S_{2,2}$ 空闲, 此时在序列缓冲区 $B s_{2.2}$ 的缓冲区
工位 $b_{2,1,2}$ 中客车 $B u s_{12}$ 等待加工, 缓冲区工位 $b_{2,2,2}$ 中 客车 Bus 3 等待加工, 根据表 7 中客车属性信息, 在 工位 $W S_{2,2}$ 上, 如果选择加工客车 $B u s_{12}$, 准备时间 $T s_{12,2,2}=T s p_{2,2}=4$, 如果选择加工客车 Bus ${ }_{3}$, 准备时间 $T S_{3,2,2}=0$, 根据控制工件离开缓冲区的 SST 规则, 选 择客车 $\mathrm{Bus}_{3}$ 加工。

\subsubsection{3 排产进化过程分析}

如图 5 所示, GA 算法和 WOA 算法在进化初 始阶段收玫得非常快, 主要得益于 CA 算法和 WOA 算法的初始种群规模 $(N P=30)$ 远大于 CGA 算法和

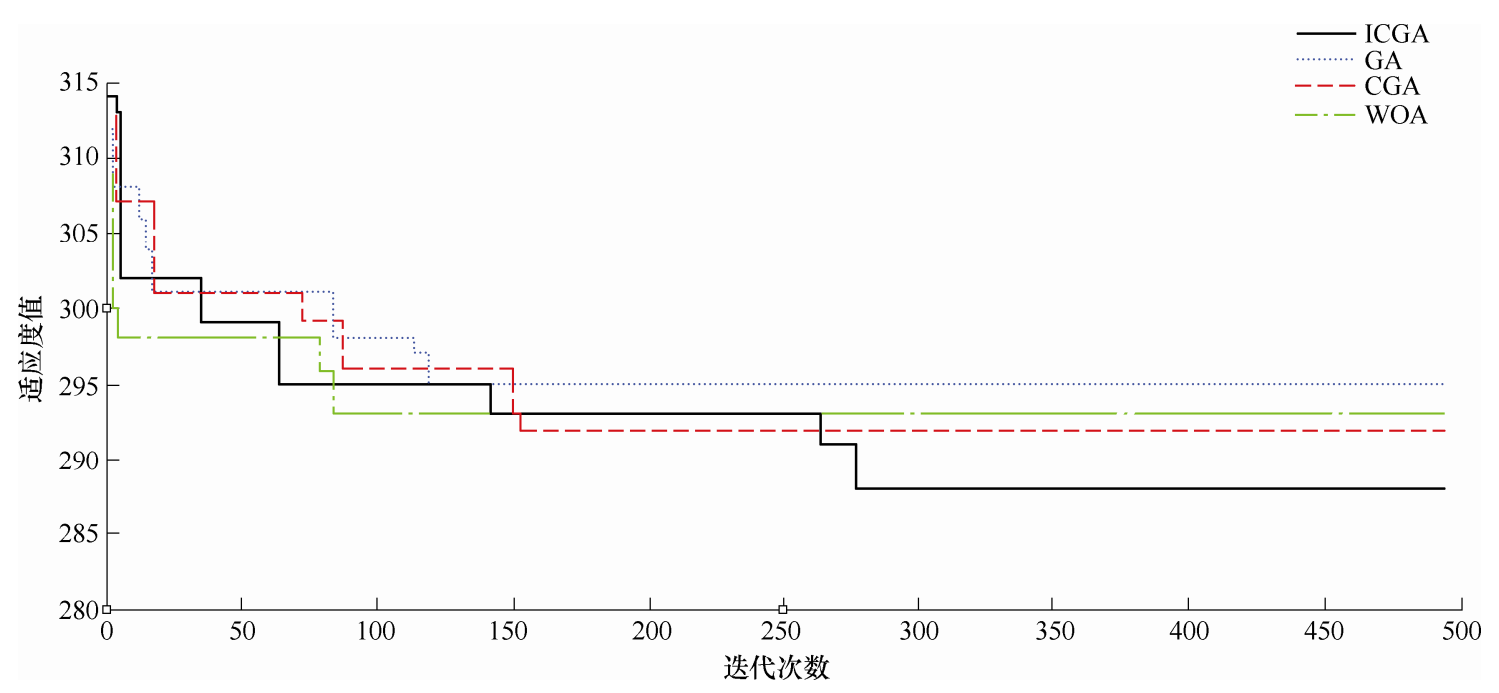

图 5 方案 $5 \sim 8$ 适应度值与训练代数关系图 
ICGA 算法 $(N P=4)$, 表现出对解空间较强的搜索能 力, 但是随着进化迭代次数增加, GA 算法和 WOA 算法早早地便落入了局部极值当中, 并分别于第 121 代和第 87 代停止进化。CGA 算法具有快速搜 索特性, 但随着进化过程概率模型中概率值分布性 快速下降, 对解空间的搜索性能也下降, 在 157 代 停止进化, 落入局部极值, ICGA 算法在初始阶段 保持了跟 CGA 算法相似的快速搜索性能, 当第 142 代出现进化停滞, 概率模型分布性下降的时候, 开 始启动高斯分布映射运算, 重新激活算法进化能力, 进一步增强算法搜索解空间的能力, 在 278 代搜索 到最优解。

\subsubsection{4 排产结果显著性统计分析}

图 6 为方案 $5 \sim 8$ 分别运行 10 次所得的最大 完工时间 $C_{\max }$, 从图 6 可以看出, 方案 5 在 10 次训练中所得最大完工时间的平均值为 300 , 是
4 种方案中优化效果最差的。方案 6 虽然有时能 够得到较优的结果, 但是其在 10 次训练中所得 到的结果不够稳定, 波动幅度较大, 有时容易落 入局部极值中, 其 10 次训练结果的平均值为 297.8 。方案 7 的训练结果要好于方案 5 和方案 6 , 但要差于方案 8 , 其平均值为 295.3 。方案 8 中第 8 次和第 10 次的训练结果为 290 , 是所有方案运 行结果的最优值。方案 8 在 10 次训练中所得最大 完工时间的平均值 291.6, 是 4 种方案中优化效果 最好的。且从图中曲线上下波动的幅度可以发现, 与其他 3 种方案相比方案 8 在 10 次训练中所得到 的最大完工时间变化幅度最小。这说明在求解带 准备时间的柔性流水车间多序列有限缓冲区排产 优化问题, 方案 8 不仅优化效果比其他 3 种方案 更好, 且其排产结果的稳定性也是 4 种方案中最 好的。

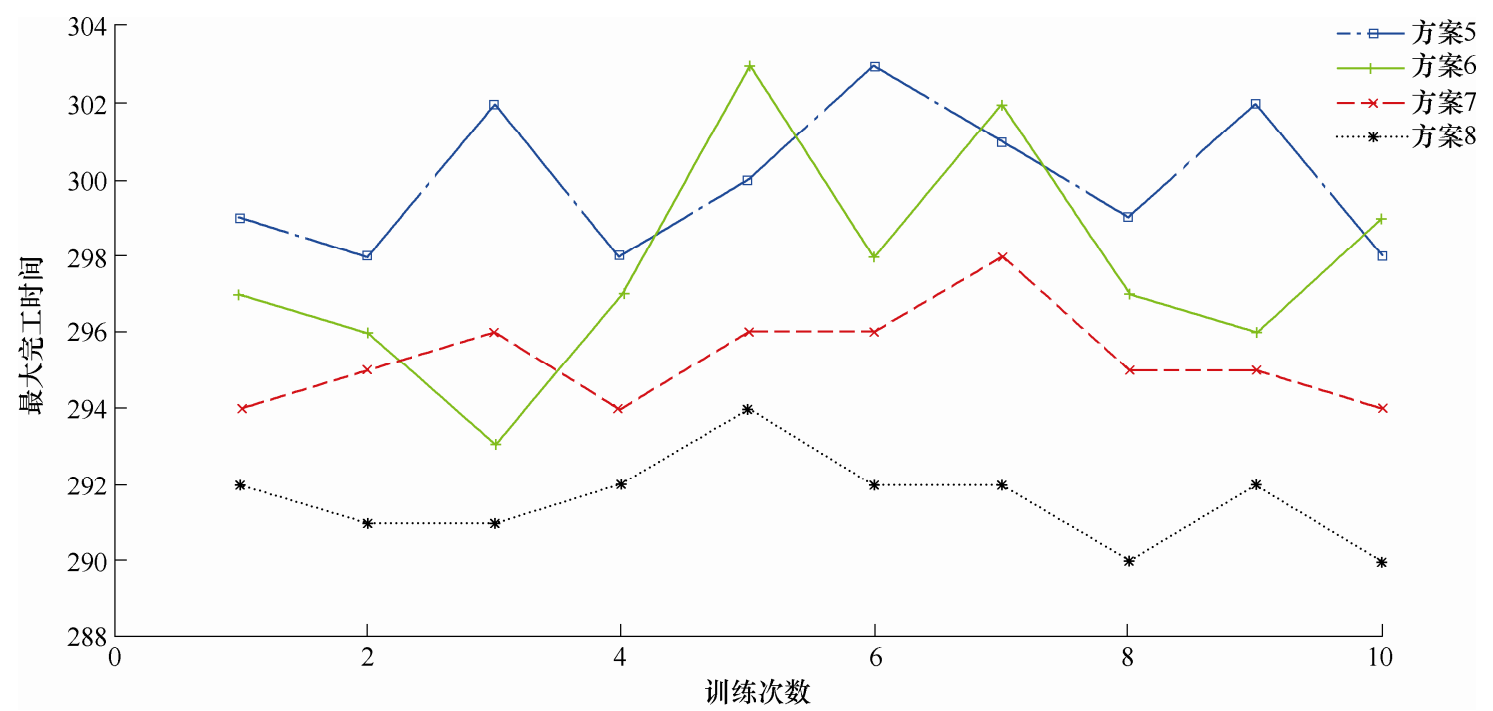

图 610 次实例测试的最大完工时间结果

\section{4 结论}

通过系统的分析研究某客车制造企业中带准备 时间的柔性流水车间多序列有限缓冲区排产优化问 题得到以下结论。

(1) 在该问题的全局优化方法研究方面, 针对 标准紧致遗传算法容易早熟收玫的问题, 提出一种 基于高斯映射的概率模型更新方式对其进行改进, 改进的紧致遗传算法在保持了标准紧致遗传算法快 速收玫特性的前提下, 增强了算法进化的活力。采 用多组大规模和小规模的算例测试了改进的紧致遗 传算法的优化效果, 并与其他群体智能算法进行了 比较, 结果表明提出的改进方法可以有效的提高紧 致遗传算法的寻优性能。
(2) 在研究和分析了带准备时间的柔性流水车 间多序列有限缓冲区的结构和特点的基础上，设计 了多种启发式规则来指导局部指派过程, 工件进入 缓冲区时，以最大序列缓冲区剩余容量优先规则为 最优先规则来控制工件在多个缓冲区的等待队列中 的分配过程，当工件出缓冲区时，以最小准备时间 优先规则为最优先规则来控制工位选择工件的过 程，有效地降低了生产过程中的阻塞时间和准备时 间对排产过程的影响。

(3) 采用实例数据测试了改进的紧致遗传算法 与局部调度规则结合的方法对于解决带准备时间 的柔性流水车间多序列有限缓冲区排产优化问题 的效果, 并设计了多组对比仿真方案, 结果表明了 本文所设计的方法在解决此类问题上的可行性和 有效性。 


\section{参 考 文 献}

[1] ZHAO F, TANG J, WANG J, et al. An improved particle swarm optimization with a linearly decreasing disturbance term for flow shop scheduling with limited buffers[J]. International Journal of Computer Integrated Manufacturing, 2014, 27(5): 488-499.

[2] 谢展鹏, 张超勇, 郡新宇, 等. 基于 Memetic 算法的有 限缓冲区流水车间调度问题[J]. 计算机集成制造系统, 2015, 21(5): 1254-1261.

XIE Zhanpeng, ZHANG Chaoyong, SHAO Xinyu, et al. Flow shop scheduling with limited buffers based on Memetic algorithm[J]. Computer Integrated Manufacturing Systems, 2015, 21(5): 1254-1261.

[3] PAN Q K, WANG L, GAO L, et al. An effective hybrid discrete differential evolution algorithm for flow shop scheduling with intermediate buffers[J]. Information Sciences, 2011, 181: 668-685.

[4] 胡蓉, 钱斌. 一种求解随机有限缓冲区流水线调度的混 合差分进化算法 [J]. 自动化学报, 2009, 35(12): 1580-1586.

HU Rong, QIAN Bin. A hybrid differential evolution algorithm for stochastic flow shop scheduling with limited buffers[J]. Acta Automatica Sinica, 2009, 35(12): 1580-1586.

[5] QING F, APPALYER S, KUNPENG L. Optimisation of flow-shop scheduling with batch processor and limited buffer[J]. Inernational Journal of Production Research, 2012, 50(8): 2267-2285.

[6] 张培文, 潘全科, 李俊青, 等. 有限缓冲区流水车间调 度的混合人工蜂群算法 $[\mathrm{J}]$. 计算机集成制造系统, 2013, 19(10): 2510-2511.

ZHANG Peiwen, PAN Quanke, LI Junqing, et al. Hybrid artificial bee colony algorithms for flowshop scheduling problem with limited buffers[J]. Computer Integrated Manufacturing Systems, 2013, 19(10): 2510-2511.

[7] ZHANG S, WONG $\mathrm{T} N$. Studying the impact of sequence-dependent set-up times in integrated process planning and scheduling with E-ACO heuristic[J]. International Journal of Production Research， 2016， 54(16): 4815-4838.

[8] SHEN L, DSUZERE P, NEUFELD J S. Solving the flexible job shop scheduling problem with sequence-dependent setup times[J]. European Journal of Operational Research, 2018, 265(2): 503-516..

[9] TRAN T T, ARAUJO A, BECH J C. Decomposition methods for the parallel machine scheduling problem with setups[J]. INFORMS Journal on Computing, 2016, 28(1): 83-95.

[10] 钟涛, 萧卫, 徐宏云, 等. 带机器准备时间的单机调度
问题的混合进化算法研究 [J]. 计算机应用研究, 2013, 30(11): 3249-3252.

ZHONG Tao, XIAO Wei, XU Hongyun, et al. Hybrid evolutionary algorithm for solving single-machine scheduling problem with setup times[J]. Application Research of Computer, 2013, 30(11): 3249-3252.

[11] BENKALAI I, REEBAINE D, GAGNE C, et al. Improving the migrating birds optimization metaheuristic for the permutation flow shop with sequence-dependent set-up times[J]. International Journal of Production Research, 2017, 55(20): 6145-6157.

[12] PAN Q K, GAO L, LI X Y, et al. Effective metaheuristics for scheduling a hybrid flow shop with sequence-dependent setup times[J]. Applied Mathematics and Computation, 2017, 303: 89-112.

[13] AN Y J, KIM Y D, CHOI S W. Minimizing makespan in a two-machine flowshop with a limited waiting time constraint and sequence-dependent setup times[J]. Computers \& Operations Research, 2016, 71: 127-136.

[14] LENSTRA J K, KAN A H G R, BRUCKER P. Complexity of machine scheduling problems[J]. Studies in integer programming, 1977, 1: 343-362.

[15] HARIK G R, LOBO F G, GOLDBERG D E. The compact genetic algorithm[J]. IEEE Transactions on Evolutionary Computation, 1999, 3(4): 287-297.

[16] DA S R R, ERIG L C R, LOPES H S. Template matching in digital images using a compact genetic algorithm with elitism and mutation[J]. Journal of Circuits, Systems, and Computers, 2010, 19(1): 91-106.

[17] 韩忠华, 朱一行, 史海波, 等. 基于改进紧致遗传算法 的柔性流水车间组批排产优化问题研究 [J]. 系统工程 理论与实践, 2016，36(6): 1617-1624.

HAN Zhonghua, ZHU Yihang,, SHI Haibo, et al. Study for the flexible flow shop scheduling problem with batch process machines based on an advanced compact genetic algorithm[J]. Systems Engineering-Theory \& Practice, 2016, 36(6): 1617-1624.

[18] 李聪波, 沈欢, 李玲玲, 等. 面向能耗的多工艺路线柔 性作业车间分批优化调度模型 [J]. 机械工程学报, 2017, 53(5): 12-23.

LI Congbo, ZHEN Huan, LI Lingling, et al. A batch splitting flexible job shop scheduling model for energy saving under alternative process plans[J]. Journal of Mechanical Engineering, 2017, 53(5): 12-23.

[19] 赵兴旺, 梁吉业. 一种基于信息熵的混合数据属性加权 聚类算法 $[\mathrm{J}]$. 计算机研究与发展，2016，53(5)： 1019-1027.

ZHAO Xingwang, LING Jiye. An Attribute Weighted Clustering Algorithm for Mixed Data Based on 
Information Entropy[J]. Journal of Computer Research and Development, 2016, 53(5): 1019-1027.

[20] ALAYKYRAN K, ENGIN O, DOYEN A. Using ant colony optimization to solve hybrid flow shop scheduling problems[J]. The International Journal of Advanced Manufacturing Technology, 2007, 35(5-6): 541-550.

[21] NERSON E, BAPTISTE P, GUPTA J N D. Solving hybrid flow shop problem using energetic reasoning and global operations[J]. Omega, 2001, 29(6): 501-511.

[22] SANTOS D L, HUNSUCKER J L, DEAL D E. Global lower bounds for flow shop with multiple processors[J]. European Journal of Operational Research，1995，80(1): 112-120.

[23] 徐华, 张庭. 混合离散蝙蝠算法求解多目标柔性作业车
间调度[J]. 机械工程学报，2016，52(18): 201-211.

XU Hua, ZHANG Ting. Hybrid discrete bat algorithm for solving the multi-objective flexible job shop scheduling problem[J]. Journal of Mechanical Engineering, 2016, 52(18): 201-211.

作者简介: 韩忠华, 男, 1977 年出生, 博士, 硕士研究生导师。主要研 究方向为生产与运作管理、企业自动化系统集成技术、车间排产与生产 调度算法的工程应用。

E-mail: hanzhonghua@sia.cn

张权(通信作者), 男, 1994 年出生, 硕士。主要研究方向为车间排产与 生产调度算法的工程应用。

E-mail: zhangq0716@163.com

史海波, 男, 1966 年出生, 博士, 研究员, 博士研究生导师。主要研究 方向为生产与运作管理、企业自动化系统集成技术、车间排产与生产调 度算法的工程应用。

E-mail: hbshi@sia.cn

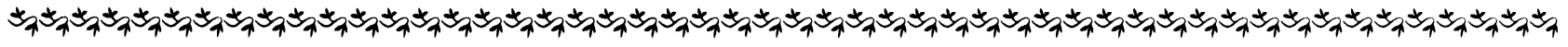

\section{(上接第 235 页)}

LI Geqiang, ZHANG Longfei, HAN Weifeng, et al. Pulsation characteristic analysis and tooth profile design of double-circular-arc helical gear pumps[J]. China Mechanical Engineering, 2018，29(2): 186-192.

[23] 孙浩林. 基于圆弧齿形的低脉动齿轮泉特性研究[D]. 哈 尔滨：哈尔滨工业大学, 2018.

SUN Haolin. Research on low-pulse external gear pump based on circular-arc gear profile[D]. Harbin: Harbin Institute of Technology, 2018.

[24] DEVENDRAN R S, VACCA A. A novel design concept for variable delivery flow external gear pumps and motors[J]. International Journal of Fluid Power, 2014, 15(3): 121-137.

[25] VACCA A, DEVENDRAN R S. A flow control system for a novel concept of variable delivery external gear pump $[\mathrm{C}] / 10$ th International Fluid Power Conference-Dresden. 2016: 263-274.

[26] 杨德贵, 钟定莲. 径向移动变量齿轮不 (马达): 中国, 85109203[P]. 1987-06-03.
YANG Degui, ZHONG Dinglian. Radial-movable variable displacement gear pump (Motor): China, 85109203[P]. 1987-06-03.

[27] WINMILL L. Adjustable-displacement gear pump: U.S., 09/734, 326[P]. 2001-09-27.

[28] 闻德生, 商旭东, 潘为圆, 等.齿轮型多泵多马达传动 系统设计与试验 $[\mathrm{J}]$. 农业机械学报，2017，48(6): 399-406.

WEN Desheng, SHANG Xudong, PAN Weiyuan, et al. Design and experiment on gear multi-pump and multi-motor driving system[J]. Transactions of the Chinese Society for Agricultural Machinery, 2017, 48(6): 399-406.

作者简介: 赵斌, 男, 1981 年出生, 博士, 副教授, 硕士研究生导师。 主要从事机电装备建模理论及智能控制、电液节能系统、液压元件等方 面的研究。

E-mail: zbtyut@126.com

权龙(通信作者), 男, 1959 年出生, 博士，教授，博士研究生导师。主 要研究方向为电液伺服及比例控制技术, 工程机械节能。

E-mail: quanlong@tyut.edu.cn 